\title{
Der Nährwert des neuen und alten Maises ${ }^{1}$ ).
}

\section{(Vergleichende Untersuchungen.) ${ }^{2}$ )}

Von

\section{Dr. med. J. J. Nitzeseu,}

Abteilungsvorsteher am physiologischen Institut der Bukarester Universität.

Die bis jetzt veröffentlichten Untersuchungen über den Nährwert des Maises lassen sich in zwei Klassen teilen. Die erste, weniger zahlreiche, enthält Studien, worin man die ganze Aufmerksamkeit auf den Stoffwechsel bei ausschliesslich mit Mais gefütterten Tieren gericbtet hat. Die andere besteht aus zahlreicheren Untersuchungen, bei welchen die Forscher darauf ausgegangen sind, den Stoffwechsel bei Menschen zu ermitteln, die einer grösstenteils aus Mais bestehenden Kost unterzogen worden sind, um durch Vergeichsversuche an Tieren, die man nur mit Mais gefüttert bat, das Verhältnis zu entdecken, welches zwischen einer Ernährung dieser Art and der Pellagra bestehen mag.

Tiere, die man ausschliesslich mit Mais ernährt hat - Meerschweinchen, Hasen, Hunde, Pferde - , halten diese Ernährung nicht lange aus; sie werden mager und sterben endlich nach einer geraumen Zeit, deren Dauer von der Gattung des Tieres bedingt wird (B e z z ol a, Lucksch, Holst, Baglioni, Centanni, Galassi usw.).

Die Ergebnisse der Untersuchungen über den Stoffwechsel bei dem Menschen deuten ebenfalls auf einen sehr géringen plastischen Nährwert der aus. Mais bestehenden Kost (Albertoni, Rossi, Tullio, Baglioni, Perroncitto usw.).

Durch die Hydrolyse des Zeins sind Abderbalden, Langstein, Osborne und Clapp zur Erkenntnis gelangt, dass, in dem Molekül desselben die folgenden Aminosäuren gänzlich fehlen: Tryptophan, Lysin und Glykokoll.

Dem Mangel an diesen Aminosäuren ist von manchen der geringere Nährwert des Maises zugeschrieben worden (A bderhalden, Osborne, Mendel, Thomas usw.)

1) In den "Denkschriften der rumänischen Akademie der Wissenschaften". Bd. 37. 1915. Sonderabdruck 5.

2) Dieses Schriftstück wurde der Redaktion bereits im Juli 1916 vorgelegt. 
In der Tat ist es durch Hinzulügung von Tryptophan zu der Zeinnahrung Rockwood, Willcock und S. Hopkins') gelungen, die Lebensdauer von Ratten zu verlängern. Mendela ${ }^{2}$ und Osborne haben anderseits die Entwicklung junger Ratten, die mit Zein als Eiweissstoff gefuttert wurden, gehemmt gesehen, hingegen ihr normales Gedeihen durch Hinzufügung von Lysin und Glykokoll bewirkt.

Manche Forseher vertreten aber die Ansicht, dass es sich hier um den Mangel an anderen, dem Stoffwechsel unentbehrlichen Stoffen handle; hierbei betont Funk den Mangel an Vitamin und Urbeanu den an Mineralstoffen, hauptsächlich den des Kaliums.

Aus dem Vorangegangenen wird also ersichtlich, dass die Frage über den Nährwert des Maises, bei weitem ungelöst, ihre ganze Bedeutung noch bebält, und, hauptsächlich wegen der engen Beziehung zwischen der Maiskost und der Pellagra, die grösste Aufmerksamkeit verdient.

Denn es gibt noch eine Seite dieser Frage, die, soviel wir wissen, bis jetzt keiner speziellen Forschung unterzogen worden ist.

Es scheint tatsächlich, dass der Näbrwert auch von dem Erntealter des Maises bedingt wird, da es empirische Beobachtungen gibt, die von diesem Standpunkte aus einen beträchtlichen Unterschied zwischen dem unmittelbar nach der Ernte genossenen und dem einoder mehrere Jahre alten Maise aufweisen.

Ebenso ist von manchen Autoren nebenbei darauf hingewiesen worden, dass der neue Mais eine kräftigere "pellagrogene Wirkung" ausübt als der alte [Proca $\left.\left.{ }^{3}\right)\right]$.

Man hat anderseits eine sehr grosse Mortalität - eine wahrhafte Epizootie - unter den Hausvögeln beobachtet, die mit frisch geerntetem Mais gefüttert wurden. Dieser Mortalität wird jedoch ein Ende gemacht, indem man den neuen Mais durch einen anderen, aus einer älteren Ernte stammenden, ersetzt [ $\left.\left.\mathrm{Chiru}{ }^{4}\right)\right]$.

In der vorliegenden Arbeit haben wir uns das Ziel gesetzt,

1) Edith Willcock and F. Gowland Hopkins, The importance of individual amino-acid in metabolism. Journal of Physiology. Vol. 35 p. 88. Dec. 1906.

2) Lafayette B. Mendel, Das Wachstum. Ergebnisse für Physiologie. Wiesbaden. 1916.

3) Dr. Proca, Cercetàri asupra pelagrei (Untersuchungen über die Pellagra). Bukarest. 1903.

4) Prof. Chiru, Raport adresat Ministeru ui de Agriculturå. 
durch vergleichende Versuche an Tieren den Nährwert des neuen und alten Maises zu bestimmen und den diesbezüglichen Unterschied zwischen beiden Arten dieses Nahrungsmittels nacbzuweisen.

\section{Erstes Kapitel. \\ Die Technik.}

Die Experimente wurden an Hühnern, Hähnen und weissen Ratten ausgeführt, somit an Tieren, deren hauptsächliche Nahrung aus Getreidekörnern besteht.

Das Geflügel wurde in Käfigen gehalten, auf deren Fussboden eine eiserne Schüssel war, die mit einem Drahtnetz bedeckt war. In dieser Schüssel sammelten sich die Fäces und der Urin. Die Schüssel konnte somit vom Geflügel nicht berührt werden. Eine zweite und dritte Zinkschüssel war in je einer Ecke des Käfigs fixiert; die eine enthielt Wasser, die andere Maiskörner.

Für die Ratten haben wir grosse Glastrichter verwendet, in deren Innern ungefähr zwischen dem mittleren und dem äusseren Drittel ein Drahtnetz fixiert war, worauf sich die Tierchen befanden. Die Fäces derselben blieben aber halb am Drahtnetz haften, während ihr Urin durch das Trichterrohr in ein daruntergesetztes Glasgefäss floss, das mit wenig Chloroform versetzt war. Der Glastrichter war oben mit einem dickeren Leinwanddeckel bedeckt.

Für alle Untersuchungen wurde eine und dieselbe Maișart aus der Bauernkultur des Bezirks Dambovitza verwendet.

Die Untersuchungen an den Hühnern haben am 18. Dezember 1911 begonnen und wurden etwa 4 Monate mit einem alten Mais gemacht. Der alte Mais, der verwendet wurde, war um eine Ernte älter.

Die Untersuchungen an den Hähnen und Ratten wurden im Oktober 1912 und 1913 begonnen. Der neue Mais war somit 2-3 Wochen, während der alte bereits 2 oder 3 Jahre nach der Ernte.

$\mathrm{Zu}$ Beginn jeder Untersuchung haben wir den Wasser-, Stickstoff- und Zuckergehalt des zum Untersuchungszwecke verwendeten Maises bestimmt.

a) Der Wassergehalt wurde durch eine indirekte Methode bestinumt: wir haben ein 1--2 g schweres, genau abgewogenes Maismehlquantum genommen und in einem Trockenschrank bei einer Temperatur von $105-110^{\circ} \mathrm{C}$ getrocknet. Die Gewichtsdifferenz zwischen dem getrockneten und nicht getrockneten Mehl ergibt das Wasserquantum des verwendeten Maismehles. 


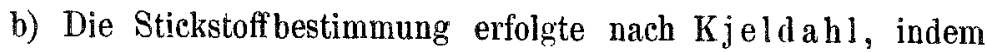
1-2 g Mehl oder zermahlene Körner mit Schwefelsäure unter Zusatz von 1-2 Tropfen Quecksilber oxydiert und das gefundene Stickstoffquantum mit dem Koeffizienten 6,25 multipliziert wurde, um die Eiweissstoffe des Maises zu berechnen.

c) Die Stärkebestimmung exfolgte, indem man das Mehl unter Zusatz von $2 \%$ Salzsäure kochte, wodurch sich die Stärke in Zucker umwandelt, der nun mit Fehling'scher Lösung titriert und die gefundene Menge mit dem Koeffizient 0,9 multipliziert wird, damit man die entsprechende Stärkemenge findet.

T a belle 1 enthält die Analysenresultate des zu unseren Untersuchungen verwendeten Maises:

Tabelle 1.

\begin{tabular}{|c|c|c|c|c|c|c|c|c|}
\hline \multirow{2}{*}{ Experimente } & \multicolumn{2}{|c|}{$\begin{array}{l}\text { Stickstoff } \\
\% \% \text { in } \mathrm{g}\end{array}$} & \multicolumn{2}{|c|}{$\begin{array}{c}\text { Eiweissstoffe } \\
\% \text { in } \mathrm{g}\end{array}$} & \multicolumn{2}{|c|}{$\begin{array}{l}\text { Stärke } \\
0 \% \text { in } \mathrm{g}\end{array}$} & \multicolumn{2}{|c|}{$\begin{array}{l}\text { Wasser } \\
\% \text { in } \mathrm{g}\end{array}$} \\
\hline & $\begin{array}{l}\text { neuer } \\
\text { Mais }\end{array}$ & $\begin{array}{l}\text { alter } \\
\text { Mais }\end{array}$ & $\begin{array}{l}\text { neuer } \\
\text { Mais }\end{array}$ & $\begin{array}{l}\text { alter } \\
\text { Mais }\end{array}$ & $\begin{array}{l}\text { neuer } \\
\text { Mais }\end{array}$ & $\begin{array}{l}\text { alter } \\
\text { Mais }\end{array}$ & $\begin{array}{c}\text { nener } \\
\text { Mais }\end{array}$ & $\begin{array}{l}\text { alter } \\
\text { Mais }\end{array}$ \\
\hline Hühner & 1,418 & $1,4: 30$ & 8,863 & 8,938 & 62,92 & 63,99 & 17,02 & 14,05 \\
\hline $\begin{array}{l}\text { Hähne und } \\
\text { Ratten }\end{array}$ & 1,340 & 1,420 & 8,375 & 8,875 & 61,96 & 64,80 & 17,54 & 12,25 \\
\hline
\end{tabular}

DieNahrung wurde zuerst abgewogen und täglich um dieselbe Stunde verteilt. Die zurückgebliebenen Reste des vergangenen Tages wurden genau abgewogen, damit man genau den täglichen Verbrauch kennt.

Die Ausscheidungsprodukte des Geflügels (Harn und Fäces) werden täglich in Glasgefässen, mit einer $2 \%$ igen Lithiumlösung (Lithiumhydroxyd) versetzt, mit Spuren Chloroform aufgehoben, wodurch jede Gärung verhindert wird. Es werden für jedes Tier separat die Ausscheidungsprodukte von 4 Tagen gesammelt und nach je 4 Tagen die Exkretionsprodukte und die Tiere gewogen.

Bei den Ratten wird der Urin von 3 Tagen aufgehoben und in Glasgefässen mit wenig Chloroform versetzt, die auf den Drahtnetzen in den Trichtern zurückgebliebenen Fäces dagegen werden in Glasgefässen gesammelt und ebenfalls mit wenig Chloroform versetzt.

Die Zahlen von den nächstfolgenden Tabellen beziehen sich auf Serien von je 4 Tagen für die Hühner und die Hähne und von je 3 Tagen für die Ratten.

In den Ausscheidungsprodukten habe ich bestimmt: die Harnsäure beim Geflügel, den Harnstoff bei Ratten, den Gesamtstickstoffgehalt aus dem Harn und den Fäces bei den Ratten, aus dem Extrakt 
und Residium beim Geflügel und den unverdaut aus den Fäces eliminierten Mais. Für jede dieser Bestimmungen sind folgende Methoden angewendet worden.

\section{a) Die Extraktion und die Dosierung der Harnsäure.}

Eine wesentliche Schwierigkeit beim Studium des Stoffwechsels bei den Vögeln stellt die Tatsache dar, dass der Harn, welcher die letzten Disassimilationsprodukte der Stickstoffverbindungen enthält, mit den Fäces gemischt ist. $\mathrm{Kossa}^{1}$ ) hat auf chirurgischem Wege einen Annus praeternaturalis gemacht, um den Urin separat von den Fäces aufzufangen. Es ist eine leichte Operation und wird von den Vögeln vertragen, wenn dieselben entsprechend behandelt werden. So haben wir einen operierten Hahn gehabt, der 2 Monate gelebt hat, und eine operierte Henne, die 3 Monate gelebt hat. Trotzdem müssen wir so weit als möglich, besonders bei Stoffwechseluntersuchungen, solche Operationen vermeiden, welche im Experimente ein neues Element darstellen, dessen Anteil schwer zu bestimmen ist.

Deshalb ist die Methode von Kossa, wie wir weiter unten sehen werden, noch weit davon entfernt, einer genauen biologischen Untersuchung zu entsprechen.

Zur Extrahierung der Harnsäure verfährt Kossa folgendermassen: Ein Volumen Urin wird mit einem gleichen Volumen Alkohol versetzt und mit wenig $\mathrm{SO}_{4} \mathrm{H}_{2}$ behandelt. Den Titer der $\mathrm{SO}_{4} \mathrm{H}_{2}$ gibt der Autor nicht an, und nach 24 Stunden, während welcher Zeit sich die Harnsäure niederschlägt, dekantiert sich die Flüssigkeit. Der Rückstand wird auf ein Wasserbad gestellt, um den Alkohol zu verdampfen, dann neuerdings in $10-20 \mathrm{ccm}$ reiner $\mathrm{SO}_{4} \mathrm{H}_{2}$ gelöst und noch 200-400 ccm 90\% igen Alkohol hinzusetzt. Die Harnsäure schlägt sich neuerdings nieder, wird: auf einem trockenen Filter anfgefangen und abgewogen.

Zusammen mit Herrn Professor Athanasiu haben wir die Harnsäure möglichst vollkommen aus dem Vogelharn und den Fäces extrahiert. Zu dem Zwecke war es notwendig, die Harnsäure in lösliche Verbindungen überzuführen, zum Beispiel Na- oder K-Urat. Anfangs haben wir eine Mischung von Na-Bikarbonat und Na-Borat, später $2 \%$ ige Lösungen von Na- oder K-Lauge angewandt. Durch. die Einwirkung dieser Lauge quillt der Schleim auf, der in grosser Menge in den Vogelfäces vorhanden ist, so dass die Filtration

1) Kossa, Die quantitative Bestimmung der Harnsäure im Vogelharn. Zeitschr. f. physiol. Chem. Bd. 47 S. 1-4. 1906. 
schwer, ja sogar unter Druck unmöglich ist. Wir haben dann Lithiumhydroxyd angewendet, welches den viskösen Charakter des Schleimes zum Verschwinden bringt und auf diese Weise die Filtrierung ermöglicht. Das Lithiumurat ${ }^{1}$ ) ist bedeutend leichter löslich als $\mathrm{Na}$ - und K-Verbindungen.

Ich habe folgende Methode angewendet: man vermischt den Harn und die Fäces der einen Serie und kocht 5-10 Minuten lang unter fortwährendem Schütteln $a b$; dann filtriert man unter Druck. Das Filtriergefäss mit dem Rückstand wird dreimal mit eimer warmen $2 \%$ igen Lithiumlösung gewaschen. Die filtrierte Flüssigkeit ${ }^{2}$ ) und der Extrakt wird abgemessen und hierauf aus demselben in folgender Weise die Harnsäure ausgezogen: man nimmt eine genau abgemessene Menge dieser Flüssigkeit, versetzt mit einem gleichen Volumen $9 \%$ igem Alkobol, der mit im Verhältnis von $10 \% \quad \mathrm{H}_{2} \mathrm{SO}_{4}$ angesäuert ist ${ }^{3}$ ).

Das Lithiumurat zersetzt sich durch die Einwirkung der Schwefelsäure, und es bildet sich Lithiumsulfat; die Harnsäure dagegen schlägt sich nieder und kristallisiert. Zwecks einer grösseren Reinigung wird sie auf einem Filter aufgefangen und neuerdings in $2 \%$ iges Lithiumhydroxyd übergeführt und mit angesäuertem Alkohol gefällt. Diese Reinigungsoperation wird noch ein- bis zweimal wiederholt und zuletzt auf einem trockenen Filter aufgefangen unter wiederholtem Waschen mit $90 \%$ igem Alkohol ${ }^{4}$ ), um die letzten Spuren $\mathrm{SO}_{4} \mathrm{H}_{2}$ zu entfernen; dann wird getrocknet und gewogen. Die Waschungen mit Alkohol müssen vorsichtig und öfters gemacht werden. Der Alkohol muss nur $1-2 \mathrm{~mm}$ den oberen Filterrand überschreiten. Auf diese Weise erhält man eine relativ reine Harnsäure. Um sich von deren Reinheit zu überzeugen, bestimmt man den Stickstoff nach der Methode von Kjeldahl.

Auf der Tabelle 2 sind die Zahlen für die Harnsäure wiedergegeben, die in der erwähnten Art extrahiert wurde, sowie die Zahlen, die wir mit Harnsäure "Poulene" erhalten baben, welche

1) $100 \mathrm{ccm} 2 \%$ iges Lithium löst bis $205,6 \mathrm{~g}$ Harnsäure auf.

2) Das ist das Extrakt, in welchem der Stickstoff dosiert wurde zur Bestimmung des Harnsäurekoeffizienten und des ausgeschiedenen Gesamtstickstoffwertes. Der Rückstand rom Filter ist das Residium, in welchem der Stickstoff und der unverdante Mais bestimmt wurde.

3) Die Anwendung des mit $\mathrm{SO}_{4} \mathrm{H}_{2}$ angesäuerten Alkohols zur Präzipitierung der Harnsäure ist von Kos s a eingeführt worden.

4) Mit warmem Alkohol erzielt man bessere Resultate bei der vollständigen Reinigung des Filters von den Spuren der $\mathrm{H}_{2} \mathrm{SO}_{4}$. 
als sehr reine Säure gilt, als auch die Zahlen, die wir aus dem Harn der Vögel mit Annus praeternaturalis erbalten haben.

Tabelle 2.

\begin{tabular}{|c|c|c|c|}
\hline & $\begin{array}{c}N \text { der Harn- } \\
\text { säure, } \\
\text { theoretische } \\
\text { Ziffer per } \% / 0\end{array}$ & $\begin{array}{c}\mathrm{N} \text { der Harn- } \\
\text { säure, die } \\
\text { gefundene } \\
\text { Ziffer per } \%\end{array}$ & $\begin{array}{c}\text { Differenz } \\
\text { in Minus } \\
\text { per } \%\end{array}$ \\
\hline $\begin{array}{l}\text { 1. Harnsäure "Pouleuc" . . . . . } \\
\text { 2. Von uns extrahierte Harnsäure aus } \\
\text { dem Gemisch Harn und Fäces (das } \\
\text { Mittel von } 40 \text { Extraktionen) . . } \\
\text { 3. Von uns extrahierte Harnsäure aus } \\
\text { reinem Urin von Hähnen mit Anus } \\
\text { praeternaturalis (das Mittel von fünf } \\
\text { Extraktionen) . . . . . . . . }\end{array}$ & 33,333 & 33,029 & 0,304 \\
\hline
\end{tabular}

Das Produkt, welches wir somit mit Hilfe des Lithiumhydroxyds erhalten baben, ist relativ reine Harnsäure. Diese Methode ist besser als die Methode von Kossa. abgesehen von der sonst bereits erwähnten Tatsache, dass Kossa von dem reinen, nur durch eine Operation erhaltenen Vogelharn, wodurch ein neues Element unter die Lebensbedingungen des Versuchstieres eingeführt wird, ausgeht; aber selbst für den, reinen Harn ist unsere Methode besser. Wir haben die Harnsäure nach der Methode von $\mathrm{Kossa}$ und nach der unserigen extrahiert. Der gefundene Stickstoff der Harnsäure war nach der Methode von Kossa 29,551\% (das Mittel von vier Extraktionen), somit eine Differenz von $3,782 \%$ gegenüber der theoretischen Zahl.. Diese Differenz erklärt sich wahrscheinlich durch die Tatsache, dass während des Trocknens auf dem Wasserbad ein Teil der Harnsäure durch die $\mathrm{SO}_{4} \mathrm{H}_{2}$ zerstört wird. Dieses Moment bei der Methode von Kossa ist sehr gefäbrlich, und die Zerstörung der Harnsäure durch die Einwirkung der $\mathrm{SO}_{4} \mathrm{H}_{2}$ war augenfällig durch eine Braunfärbung des Präzipitats. Der Stickstoff der Harnsäure, die nach unserer Methode aus dem Harne derselben Vögel extrabiert war, näherte sich sehr viel mehr der theoretischen Zahl, wie wir aus der Tabelle 2 ersehen können.

Nachdem wir uns einmal überzeugt hatten; dass das nach unserer Methode extrahierte Produkt genügend reine Harnsäure war, mussten wir die Überzeugung gewinnen, dass die Extraktion durch Lithiumhydroxyd vollständig war. Um das nachzuweisen, haben wir folgende Proben gemacht:

1. Das Residium des Uringemisches mit den Fäces wurde mit 
neuen Lithiumhydroxydmengen behandelt, und zwar haben die Versuche negative Resultate ergeben insofern, als durch angesäuerten Alkohol keine neue Präzipitierung der Harnsäure hervorgerufen wurde.

2. Bei der Nachprüfung auf Harnsäure in dem Residium nach der Methode von Herzfeld ${ }^{1}$ ), deren Empfindlichkeit ${ }^{2}$ ) sehr gross ist, haben wir meistens negative und einige Male schwach positive Resultate erhalten.

3. Wir haben die innerhalb 24 Stunden bei derselben Henne mit Anus praeternaturalis und bei derselben Diät die ausgeschiedene Harnsäure sowohl im reinen Harn als auch im Gemisch von Harn und Fäces bestimunt und folgende Zahlen gefunden:

Harnsäure für 24 Stunden:

1. Harn und Fäces ......... . . 0,918 g $\left\{\begin{array}{l}\text { Das Mittel von vier } \\ \text { Bestimmungen variiert } \\ \text { zwischen } 0,801-1,089\end{array}\right.$

2. Reiner Harn . . . . . . . 0,975 g $\left\{\begin{array}{c}\text { Das Mittel von fünf } \\ \text { Bestimmungen variiert } \\ \text { zwischen } 0,828-1,150 \mathrm{~g}\end{array}\right.$

Die Methode der Harnsäureextraktion aus dem Gemisch Harn und Fäces von den Vögeln durch Lithiumhydroxyd ist eine gute Methode, weil die Extraktion eine vollkommene ist und die extrahierte Harnsäure sehr rein ist.

b) Den Harnstoff aus dem Rattenharne haben wir mit Natriumhypobromit bestimmt, indem wir das Urometer von Lunge angewendet haben.

o) Um den unverdauten Mais aus den Fäces und den Residien zu erkennen, haben wir die Stärke durch Verzuckerung mit $2 \% \mathrm{BCl}$ bestimmt und den Traubenzucker mit F e hling 'scher Lösung titriert.

\section{Zweites Kapitel.}

\section{Ernährungsstoffwechsel.}

\section{A. Das Experiment an Hühnern.}

Das erste Experiment wurde am 18. Dezember 1911 an sechs Hühnern, die bezüglich des Gewichts und Alters gleich waren, gemacht. Drei unter ihnen wurden mit Mais aus der Ernte des Jahres 1911 (geerntet im September), die anderen drei dagegen mit Mais aus der Ernte des Jahres 1910 gefüttert. In die erste Gruppe wurden die grössten eingereiht:

1) Herzfeld, Centralbl. f. innere Med. 1912.

2) Indem wir immer verdünntere Harnsäurelösungen (Poulenc) angewendet haben, haben wir gefunden, dass die Herzfeld 'sche Realstion noch bis zu einer Verdünnung von $1 / 1000000$ möglich ist. 


\begin{tabular}{|c|c|}
\hline 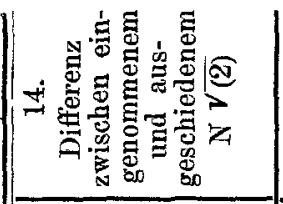 & 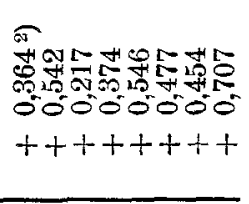 \\
\hline 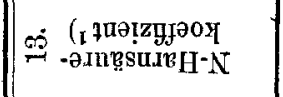 & 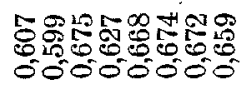 \\
\hline 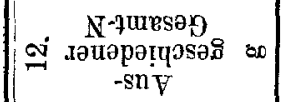 & 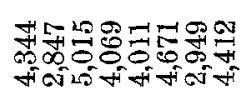 \\
\hline$\stackrel{\text { untpisey }}{\text { uəp sng } \mathrm{N}}$ so & 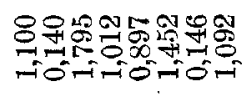 \\
\hline 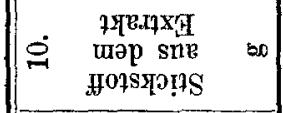 & 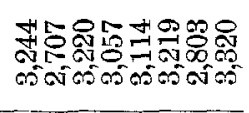 \\
\hline 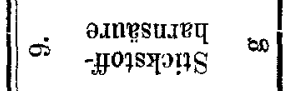 & 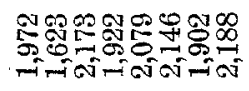 \\
\hline 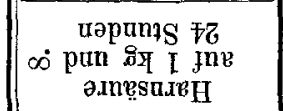 & 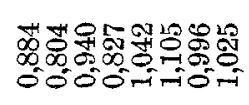 \\
\hline 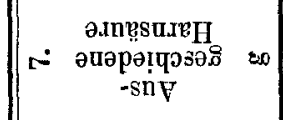 & 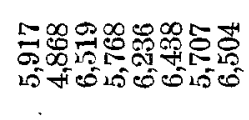 \\
\hline 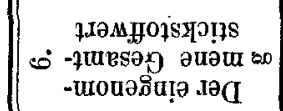 & 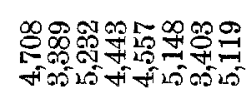 \\
\hline 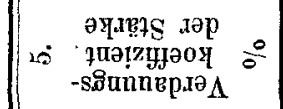 & 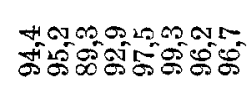 \\
\hline 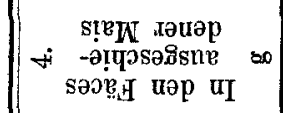 & 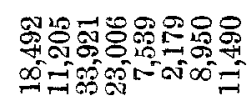 \\
\hline 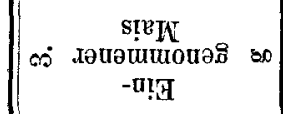 & พด \\
\hline 总 & 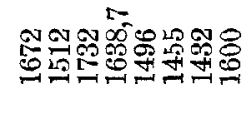 \\
\hline$\stackrel{\grave{\Phi}}{\Xi}$ & 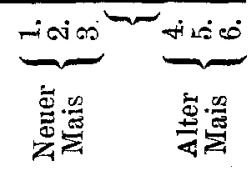 \\
\hline
\end{tabular}

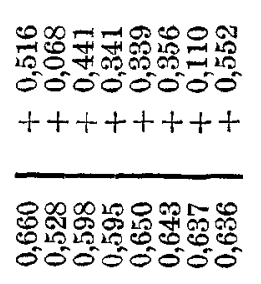

8응 Tosecticoto

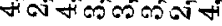

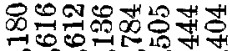

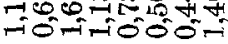

क⿻

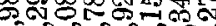

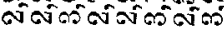

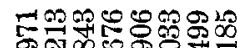
नi-ifiñ

$\stackrel{\oplus}{0}$ 잉 $190 \%$ б0́0 $\exists$

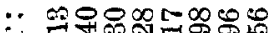

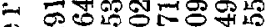

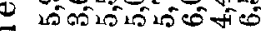
ב :

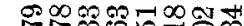

$550 \%$

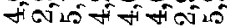

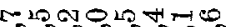

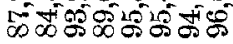

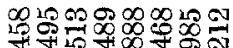

F +20 स $\infty$ \%

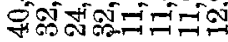

$n \cos$

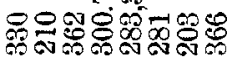

월올욜

雷 0

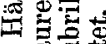

r.

政

要娄

四

-

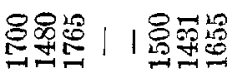

里 +

영영

过兽

\begin{tabular}{|c|c|}
\hline 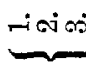 & $\underbrace{+2 \times 0^{\circ}}$ \\
\hline 离营营 & 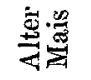 \\
\hline
\end{tabular}




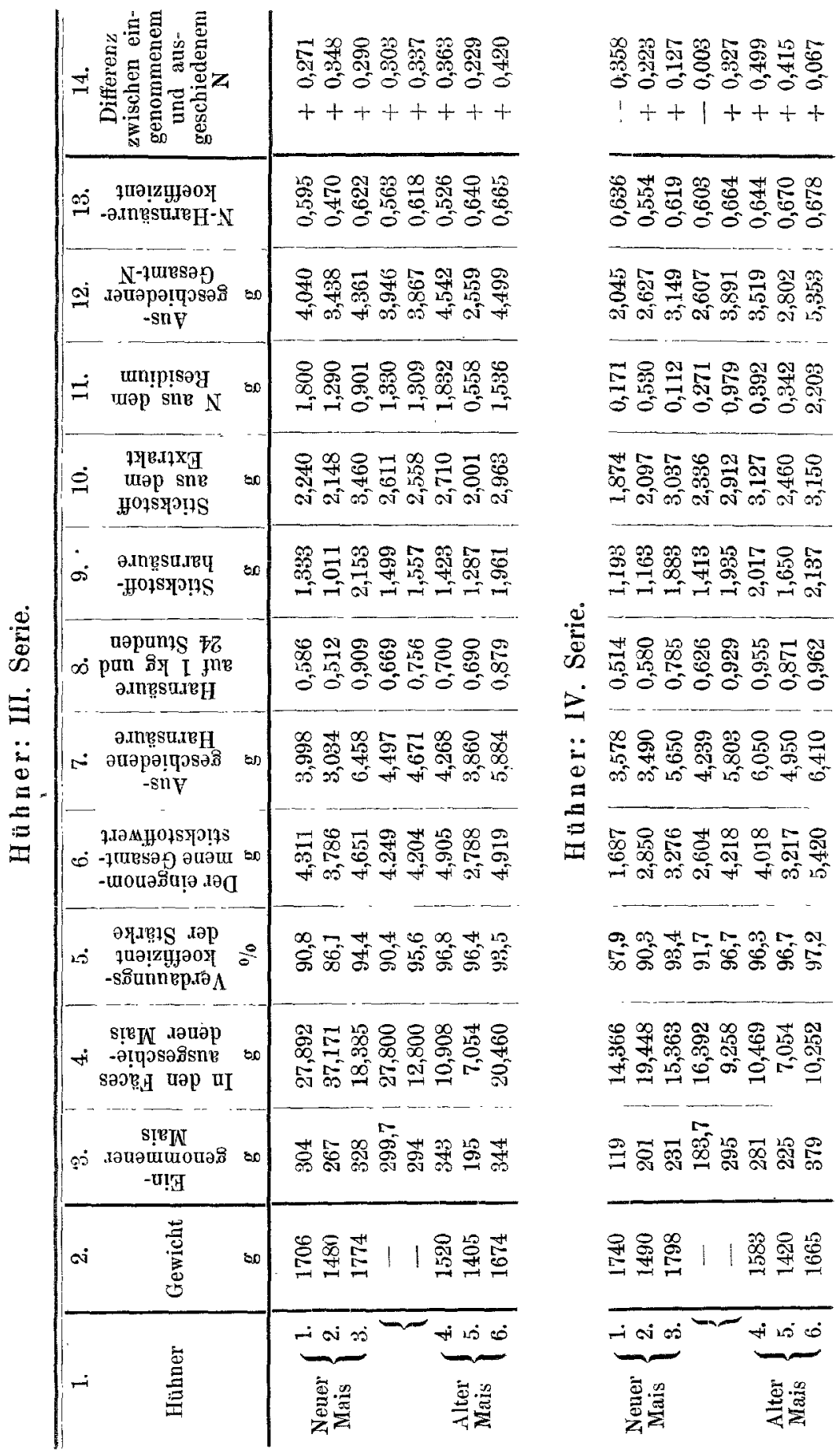




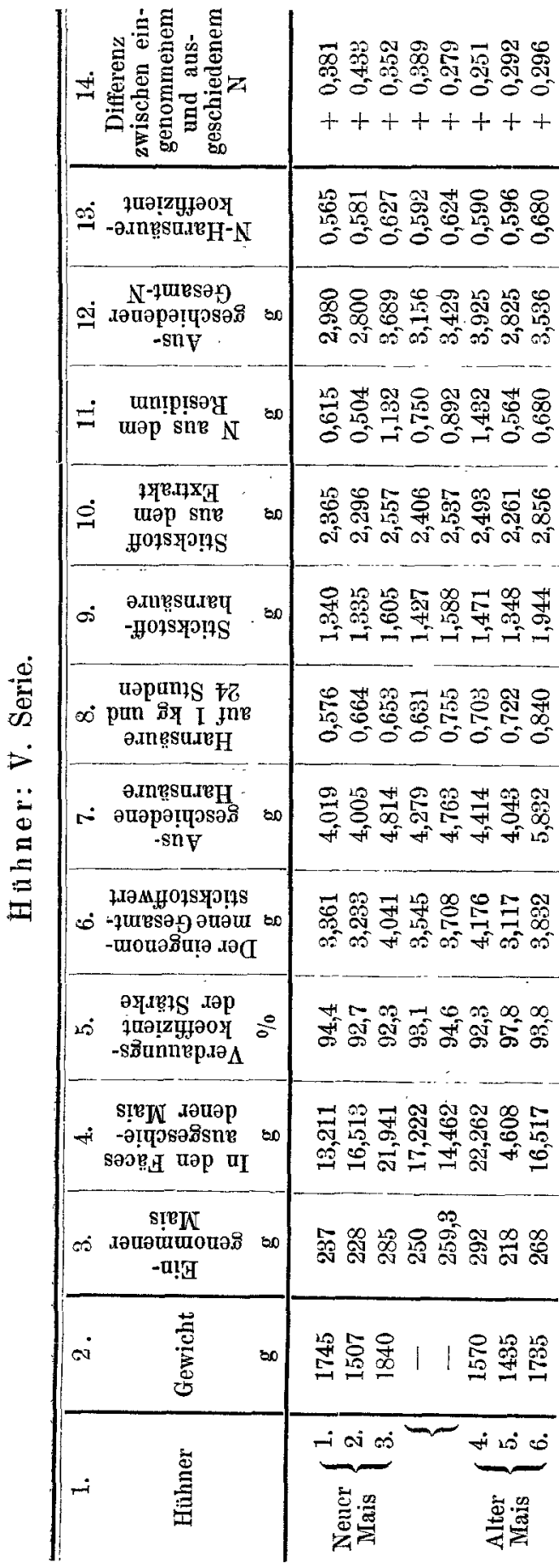

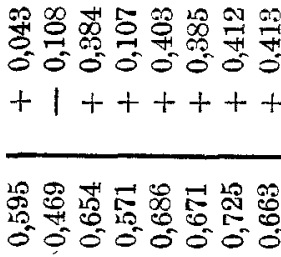

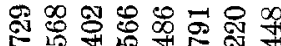

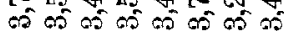

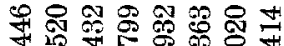

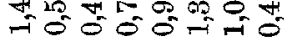

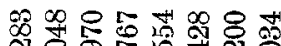
की कर की कर कर को की की

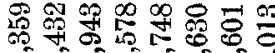

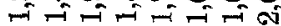

$\frac{0}{0}$

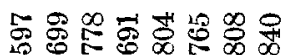
की

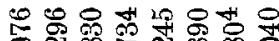
सी

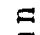
$\square$

용유융ำ की मी की की मी की की

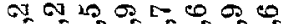

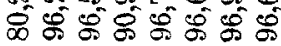

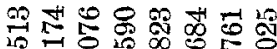
ती की की की

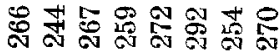

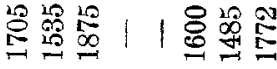

\begin{tabular}{|c|c|}
\hline ته & $+20^{\circ}$ \\
\hline $\begin{array}{l}\overline{9} \\
\overline{0} \\
\bar{Z}\end{array}$ & 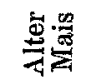 \\
\hline
\end{tabular}




\begin{tabular}{|c|c|}
\hline 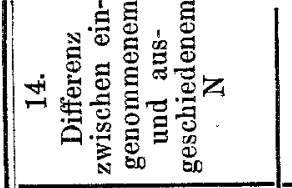 & 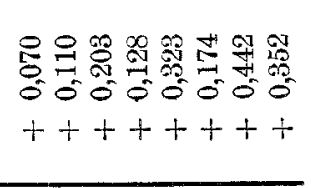 \\
\hline 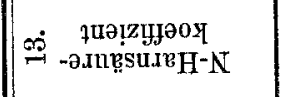 & 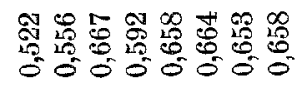 \\
\hline 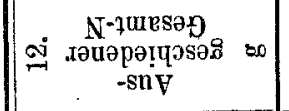 & 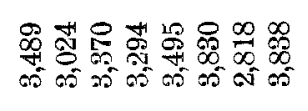 \\
\hline 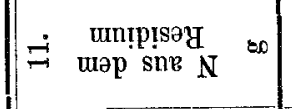 & 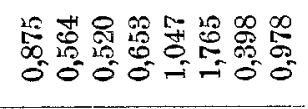 \\
\hline 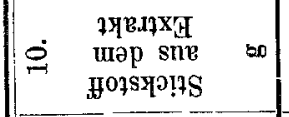 & 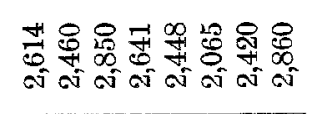 \\
\hline 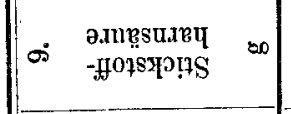 & 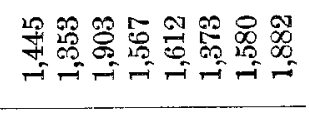 \\
\hline 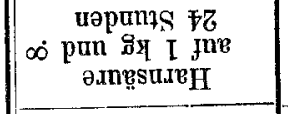 & 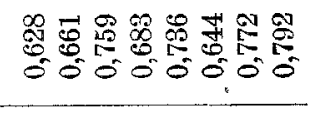 \\
\hline 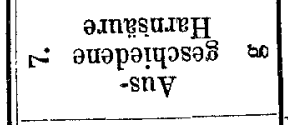 & 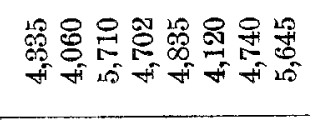 \\
\hline 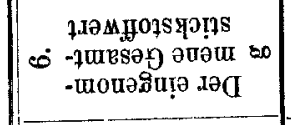 & 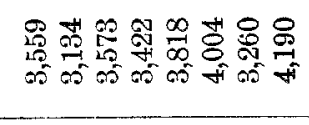 \\
\hline 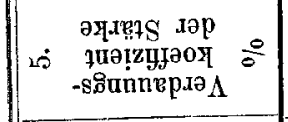 & 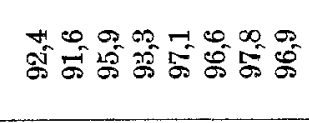 \\
\hline 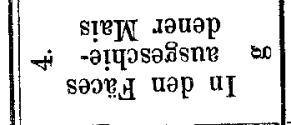 & 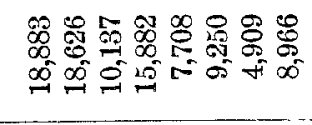 \\
\hline 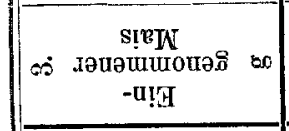 & 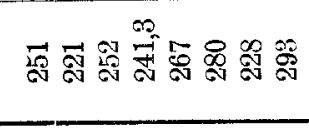 \\
\hline 㞭 & 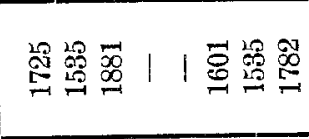 \\
\hline 嵌 & 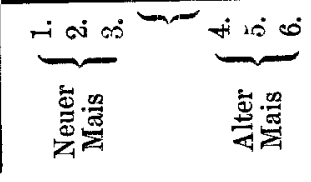 \\
\hline
\end{tabular}

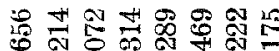

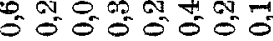

$+t+t+t+$

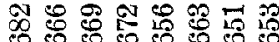

今0

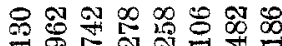

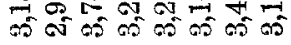

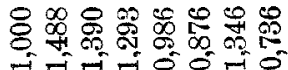

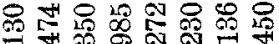
की चू की जी की की की

ำ If

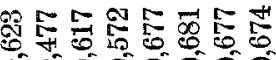
की 0 की 000

8 융용요원용

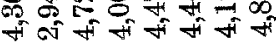

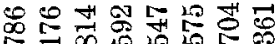

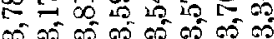

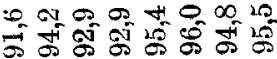

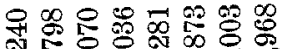
สิ

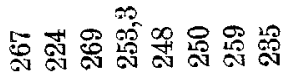

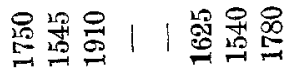

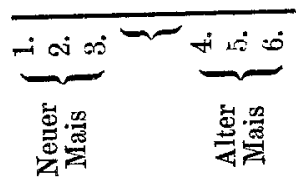




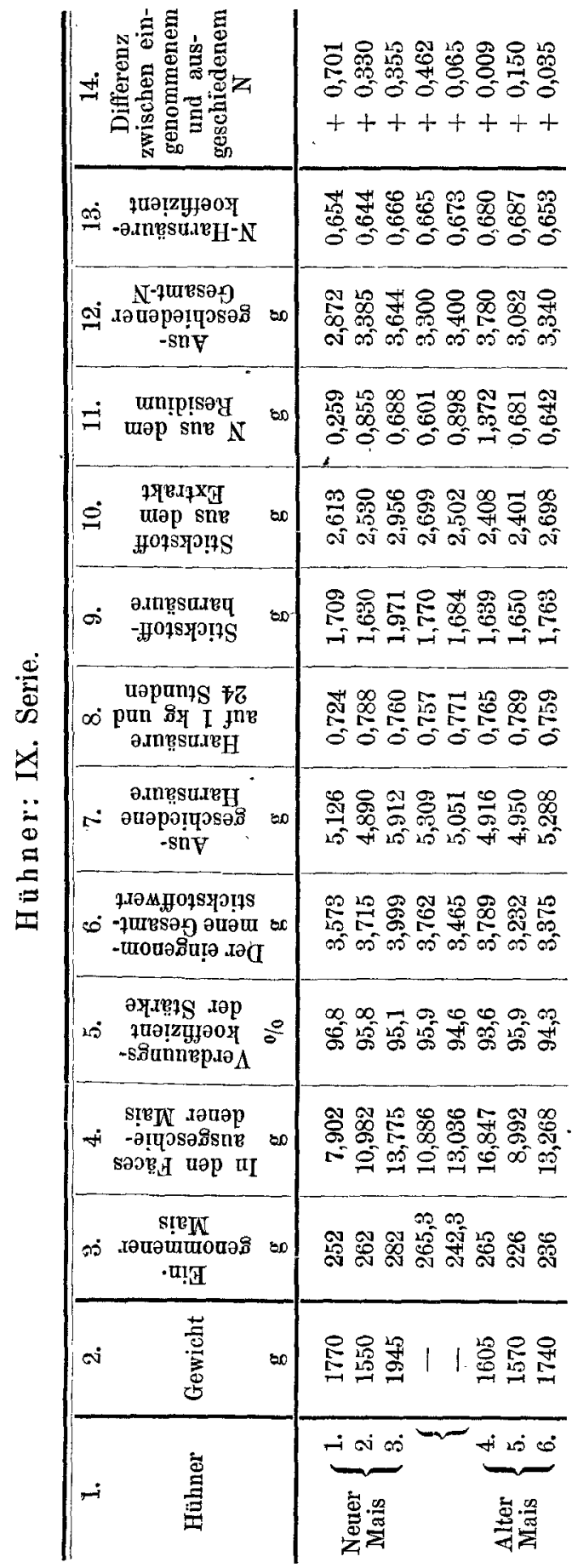

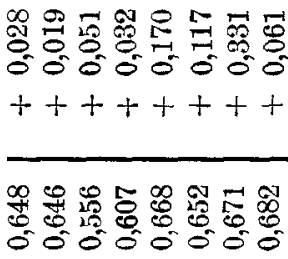

웡 10 की की की कर की की कर की

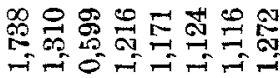

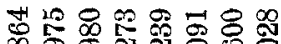
मीं की की की की की

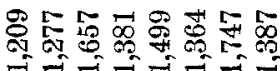

బ -

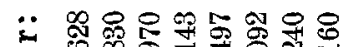

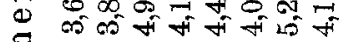

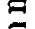

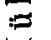

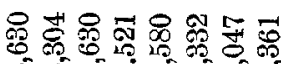
की कर कर कर कर कर सी मी

0 o 190 is 0.4

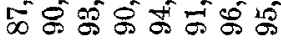

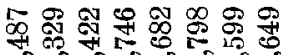

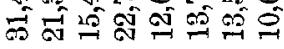

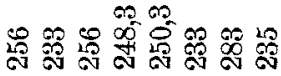

윤

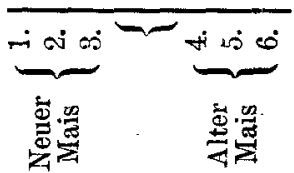


Hühner: Die Mittelwerte der 18. Dezember 1911 bis

\begin{tabular}{|c|c|c|c|c|c|c|c|c|c|c|}
\hline 1. & 2. & 3. & 4. & 5. & 6. & 7. & 8. & 9. & 10. & 11. \\
\hline \multirow[t]{2}{*}{ Hübner } & \multicolumn{2}{|c|}{$\begin{array}{l}\text { I. Serie } \\
\text { Mais }\end{array}$} & \multicolumn{2}{|c|}{$\begin{array}{c}\text { II. Serie } \\
\text { Mais }\end{array}$} & \multicolumn{2}{|c|}{$\begin{array}{c}\text { III. Serie } \\
\text { Mais }\end{array}$} & \multicolumn{2}{|c|}{$\begin{array}{c}\text { IV. Serie } \\
\text { Mais }\end{array}$} & \multicolumn{2}{|c|}{$\begin{array}{c}\text { V. Serie } \\
\text { Mais }\end{array}$} \\
\hline & Nen & Alt & Neu & Alt & $\mathrm{Neu}$ & Alt & Neu & Alt & Nen & Alt \\
\hline $\begin{array}{l}\text { Eingenomme. } \\
\text { ner Mais in } \\
\text { Gramm. . }\end{array}$ & 319,3 & 318,7 & 300,7 & 283,3 & 299,7 & 294,0 & 183,7 & 295,0 & 250,0 & 259,3 \\
\hline $\begin{array}{l}\text { Ausgeschiede- } \\
\text { ner Mais in } \\
\text { Gramm... }\end{array}$ & 23,0 & 7,54 & 32,49 & 11,98 & 27,82 & 12,8 & 16,4 & 9,26 & 17,28 & 14,46 \\
\hline $\begin{array}{c}\text { Verdauungs- } \\
\text { koeffizient } \\
\text { der Stärke }\end{array}$ & 92,9 & 97,5 & 89,0 & 95,5 & 90,4 & 95,5 & 91,7 & 96,7 & 98,1 & 94,6 \\
\hline $\begin{array}{l}\text { Eingenomme- } \\
\text { ner Gesamt- } \\
\text { stickstoff in } \\
\text { Gramm... }\end{array}$ & 4,443 & 4,557 & 4,263 & $4,05 \mathrm{i}$ & 4,249 & 4,204 & 2,604 & 4,218 & 3,545 & 3,708 \\
\hline $\begin{array}{l}\text { Gesamte aus- } \\
\text { geschiedene } \\
\text { Harnsäure }\end{array}$ & 5,768 & 6,236 & 5,028 & 5,717 & 4,497 & 4,671 & 4,239 & 5,803 & 4,279 & 4,765 \\
\hline $\begin{array}{l}\text { Harnsäure auf } \\
1 \mathrm{~kg} \text { und } 24 \\
\text { Stunden } .\end{array}$ & 0,827 & 1,042 & 0,756 & 0,930 & 0,669 & 0,756 & 0,626 & 0,925 & 0,631 . & 0,755 \\
\hline $\begin{array}{c}\text { Der } N \text { der } \\
\text { Harnsäure in } \\
\text { Gramm. . }\end{array}$ & 1,922 & 2,079 & 1,676 & 1,906 & 1,499 & 1,557 & 1,413 & 1,935 & 1,427 & 1,588 \\
\hline $\begin{array}{l}\text { Der Gesamt- } \\
\text { sticlistoffwert } \\
\text { aus dem Ex- } \\
\text { trakte in } \\
\text { Gramm. }\end{array}$ & $3 ; 057$ & 3,114 & 2,786 & 2,928 & 2,616 & 2,558 & 2,336 & 2,911 & 2,406 & 2,537 \\
\hline $\begin{array}{l}\text { Gesamtstick- } \\
\text { stoffwert aus } \\
\text { dem Residium } \\
\text { in Gramm. }\end{array}$ & 1,012 & 0,897 & 1,136 & 0,784 & 1,380 & 1,309 & 0,271 & 0,975 & 0,750 & 0,892 \\
\hline $\begin{array}{l}\text { Der gesamte } \\
\text { ausgeschie- } \\
\text { dene Stick- } \\
\text { stoff i.Gramm }\end{array}$ & 4,069 & 4,011 & 3,922 & 3,712 & 3,946 & 3,867 & 2,607 & 3,891 & 3,156 & 3,429 \\
\hline $\begin{array}{l}\text { Der Stickstoff- } \\
\text { harnsänue- } \\
\text { koeffizient }\end{array}$ & 0,627 & 0,668 & 0,598 & 0,650 & 0,573 & 0,608 & 0,605 & 0,664 & 0,592 & 0,624 \\
\hline $\begin{array}{l}\text { Differenz zwi- } \\
\text { schen einge- } \\
\text { nommenem } \\
\text { und ausge- } \\
\text { schiedenem } \\
\text { Stickstoff. . }\end{array}$ & $+0,374$ & $+0,546$ & $+0,341$ & $+0,389$ & $+0,303$ & $+0,337$ & $=0,008$ & $+0,327$ & $+0,327$ & $\div 0,279$ \\
\hline
\end{tabular}


10 Serien (jede Serie von 4 Tagen).

27. Januar 1912.

\begin{tabular}{|c|c|c|c|c|c|c|c|c|c|c|c|}
\hline 12. & 18. & 14. & 15. & 16. & 17. & 18. & 19. & 20. & 21. & 22. & 23. \\
\hline \multicolumn{2}{|c|}{$\begin{array}{c}\text { VI. Serie } \\
\text { Mais }\end{array}$} & \multicolumn{2}{|c|}{$\begin{array}{c}\text { VII. Serie } \\
\text { Mais }\end{array}$} & \multicolumn{2}{|c|}{$\begin{array}{l}\text { VIII. Serie } \\
\text { Mais }\end{array}$} & \multicolumn{2}{|c|}{$\begin{array}{c}\text { IX. Serie } \\
\text { Nais }\end{array}$} & \multicolumn{2}{|c|}{$\begin{array}{l}\text { X. Serie } \\
\text { Mais }\end{array}$} & \multicolumn{2}{|c|}{ Mais } \\
\hline Neu & Alt & Nen & Alt & $\mathrm{Neu}$ & Alt & Neu & Alt & Neu & Alt & Neu & Alt \\
\hline 259,0 & 272,0 & 241,3 & 267,0 & 253,3 & 248,0 & 265,3 & 242,3 & 248,3 & 250,3 & 261,7 & 273,0 \\
\hline 23,59 & 8,83 & 15,89 & 7,71 & 18,04 & 11,29 & 10,89 & 13,04 & 22,75 & 12,68 & 20,81 & 10,75 \\
\hline 90,9 & 96,7 & 93,3 & 97,1 & 92,9 & 95,4 & 95,9 & 94,6 & 90,6 & 94,5 & 91,1 & 95,8 \\
\hline 3,673 & 3,889 & 3,422 & 3,818 & 3,592 & 3,547 & 8,762 & 3,465 & 3,521 & 8,580 & 3,507 & 3,704 \\
\hline 4,784 & 5,245 & 4,702 & 4,885 & 4,009 & 4,470 & 5,309 & 5,051 & 4,142 & 4,497 & 4,671 & 5,129 \\
\hline 0,691 & 0,804 & 0,683 & 0,736 & 0,572 & 0,677 & 0,757 & 0,771 & 0,589 & 0,683 & 0,680 & 0,808 \\
\hline 1,578 & 1,748 & 1,567 & 1,612 & 1,336 & 1,490 & 1,770 & 1,684 & 1,381 & 1,499 & 1,557 & 1,710 \\
\hline 2,767 & 2,554 & 2,641 & 2,448 & 1,985 & 2,272 & 2,699 & 9,502 & 2,273 & 2,289 & 2,556 & 2,606 \\
\hline 0,799 & 0,982 & 0,653 & 1,047 & 1,293 & 0,986 & 0,601 & 0,808 & 1,216 & 1,171 & 0,906 & 0,989 \\
\hline 3,566 & 2,486 & 3,294 & 3,495 & 3,278 & 3,258 & 3,800 & 3,400 & 3,489 & 3,410 & 3,463 & 3,596 \\
\hline 0,571 & 0,686 & 0,592 & $0 ; 658$ & 0,672 & 0,656 & 0,655 & 0,673 & 0,607 & 0,668 & 0,609 & 0,655 \\
\hline 0,107 & $+0,403$ & $+0,128$ & $+0,323$ & $+0,314$ & $+0,289$ & $+0,462$ & $+0,065$ & $+0,082$ & $+0,170$ & $+0,245$ & $+0,2$ \\
\hline
\end{tabular}




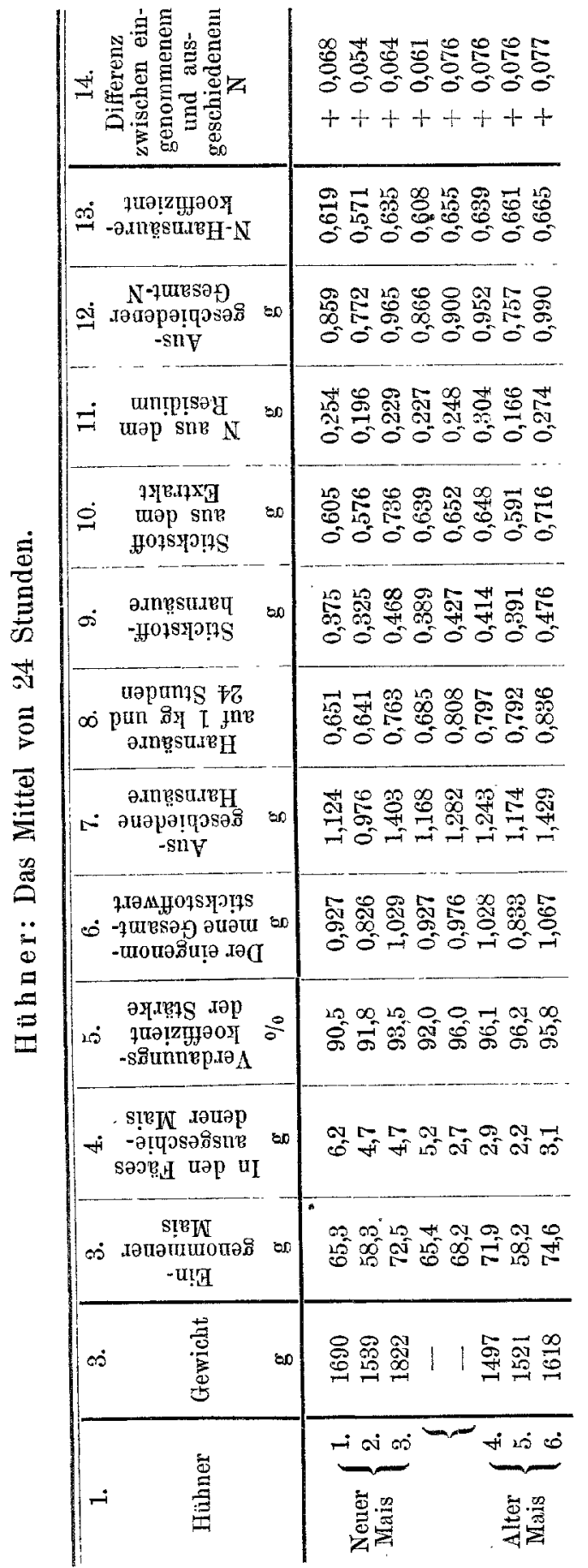

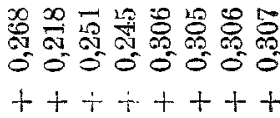

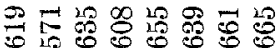

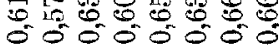

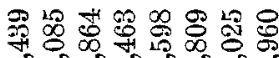

री 60 की की कर कर कर

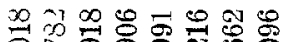

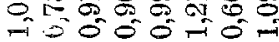

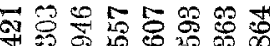

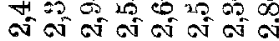

$\infty$ 엉ㅇㅇㅇㅇㅛ

等

जन

突

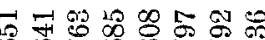

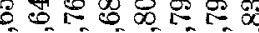

कó 00000

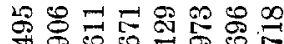

581900 出以下

कि की

$20 \infty 200,-\infty$

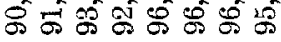

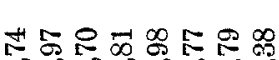

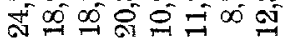

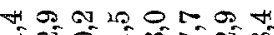

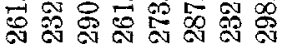

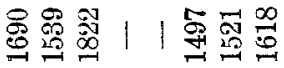

\begin{tabular}{|c|c|}
\hline - & $=0$ \\
\hline 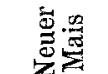 & 童产 \\
\hline
\end{tabular}


Der Nährwert des neuen und alten Maises.

\begin{tabular}{|c|c|c|}
\hline & 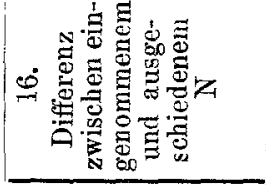 & 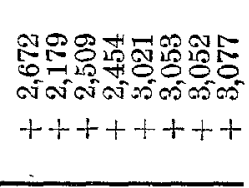 \\
\hline & 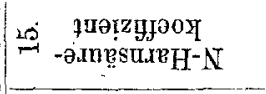 & 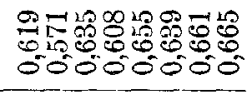 \\
\hline & 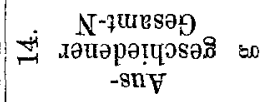 & 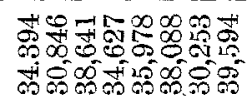 \\
\hline & $\begin{array}{l}\text { umupisoy } \\
\text { uəp sue } \mathrm{N}\end{array}$ & 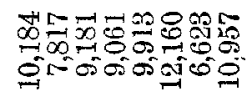 \\
\hline & 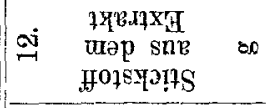 & 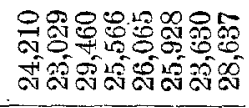 \\
\hline & 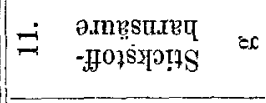 & 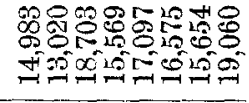 \\
\hline 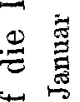 & 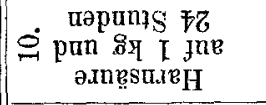 & 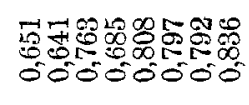 \\
\hline$\underset{\infty}{\infty}$ & 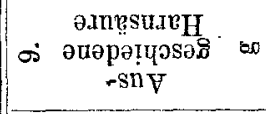 & 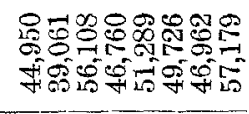 \\
\hline$\underset{\sigma}{\sigma}$ & 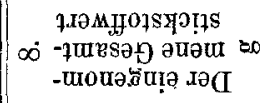 & 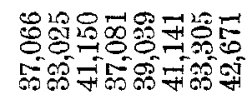 \\
\hline 递 & 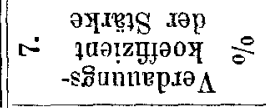 & 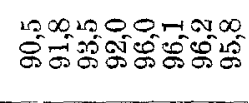 \\
\hline & 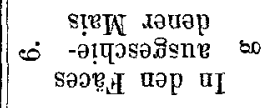 & 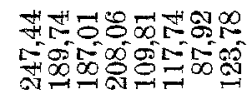 \\
\hline & 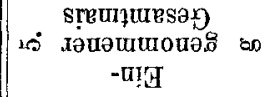 & 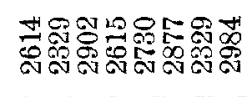 \\
\hline & 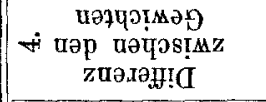 & 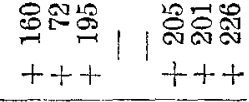 \\
\hline & 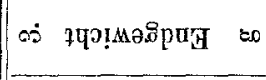 & 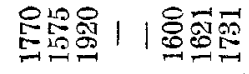 \\
\hline & 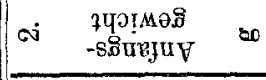 & 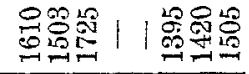 \\
\hline & 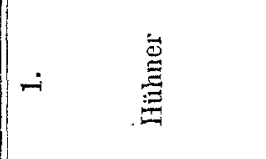 & 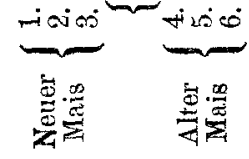 \\
\hline
\end{tabular}

\section{B. Das Experiment an Hähnen.}

Das zweite Experiment habe ich an Hähnen gemacht, ebenfalls sechs an der Zahl und geteilt in zwei Reihen von je drei. Das Fxperiment wurde am 28. Oktober 1912 begonnen und am 8. Dezember 1912 beendigt.

Die erste Reihe wurde mit Mais aus der Ernte 1912 gefüttert, geerntet zu Ende September; die zweite Reihe wurde mit Mais aus der Ernte 1908 und 1910 gefüttert. Die Hähne waren jung. aus dem Jahre 1912, somit im Aufwachsen. Auch hier wurden die stärksten mit neuem Mais gefüttert.

(Siehe die zugebörigen

Tabellen S. 292-300.) 


\begin{tabular}{|c|c|c|c|}
\hline 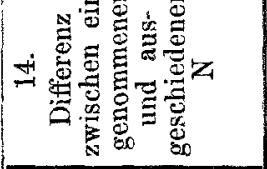 & 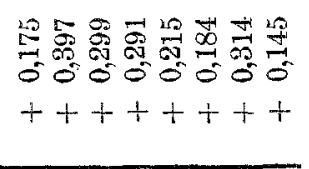 & & 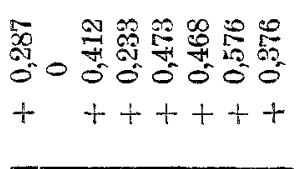 \\
\hline 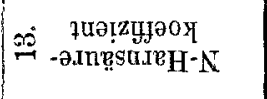 & 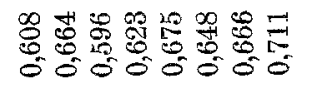 & & 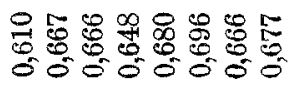 \\
\hline 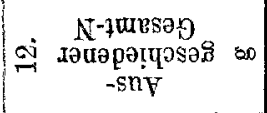 & 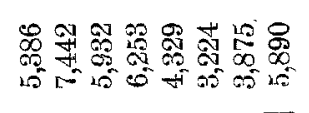 & & 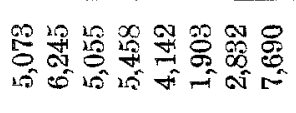 \\
\hline 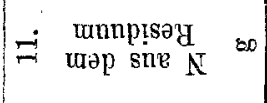 & 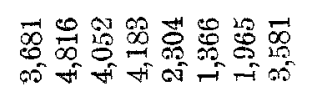 & & 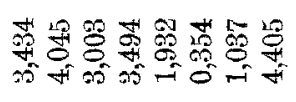 \\
\hline 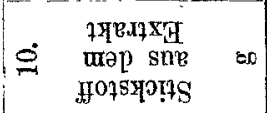 & 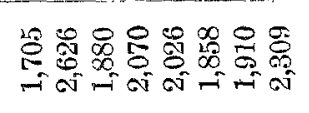 & & 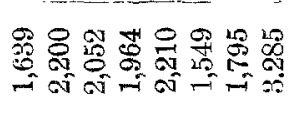 \\
\hline 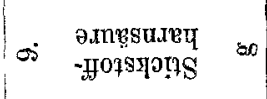 & 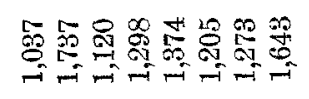 & & 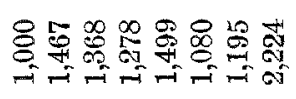 \\
\hline 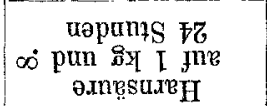 & 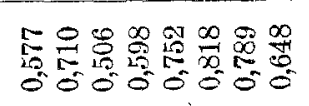 & 怤 & 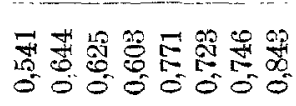 \\
\hline 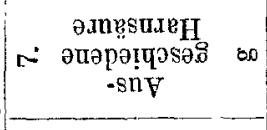 & 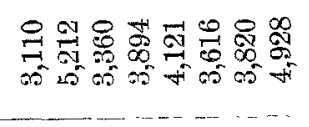 & $\ddot{0}$ & 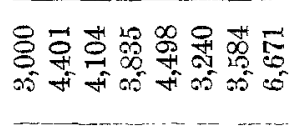 \\
\hline 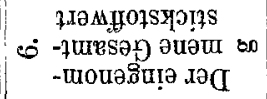 & 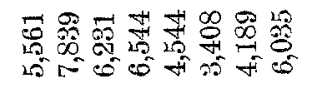 & $I$ & 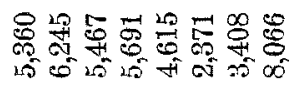 \\
\hline 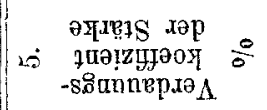 & 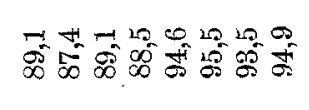 & & 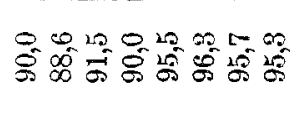 \\
\hline 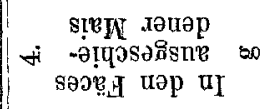 & 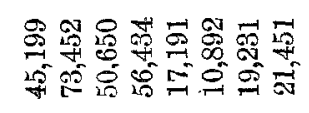 & & 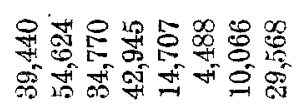 \\
\hline 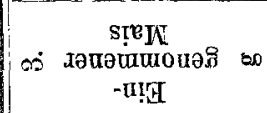 & 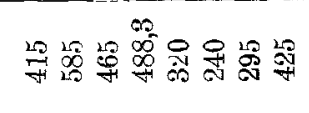 & & 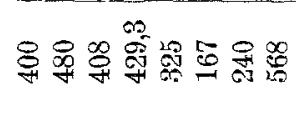 \\
\hline 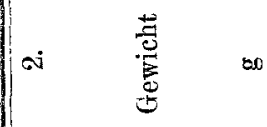 & 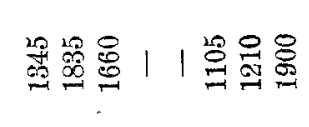 & & 胥突 \\
\hline$-i \quad$ 潈 & 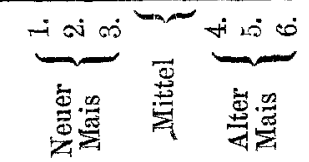 & & 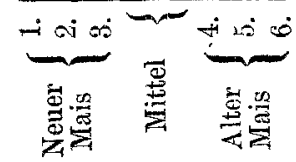 \\
\hline
\end{tabular}




\begin{tabular}{|c|c|}
\hline 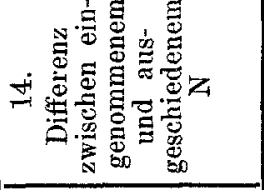 & 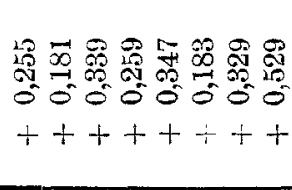 \\
\hline 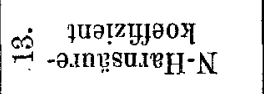 & 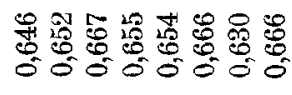 \\
\hline 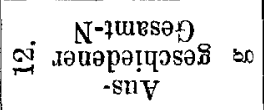 & 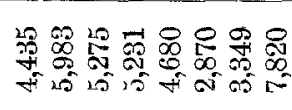 \\
\hline$=\quad$ un!̣ı!say & 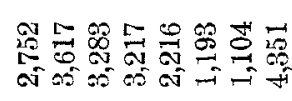 \\
\hline 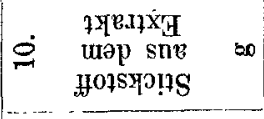 & 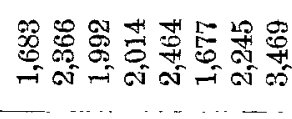 \\
\hline 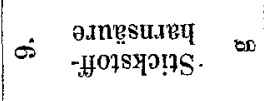 & 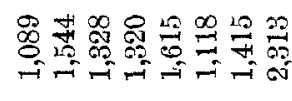 \\
\hline 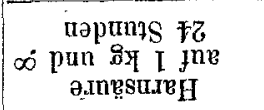 & 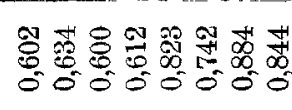 \\
\hline 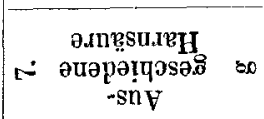 & 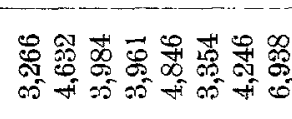 \\
\hline 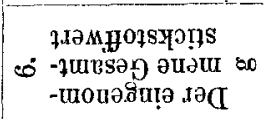 & 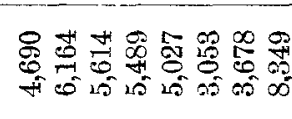 \\
\hline 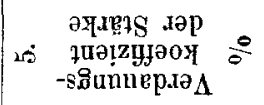 & कू \\
\hline 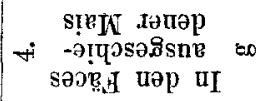 & 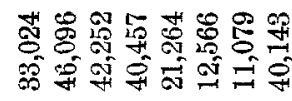 \\
\hline 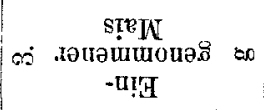 & \% \\
\hline 总 & 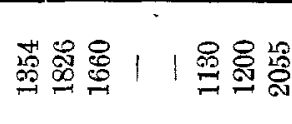 \\
\hline 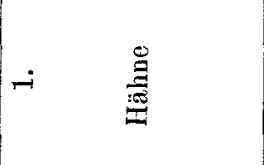 & 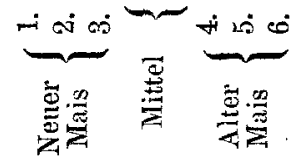 \\
\hline
\end{tabular}

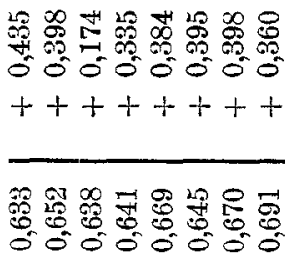

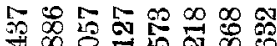
की 50 is की की की

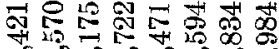

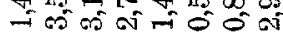

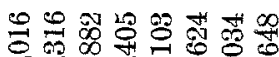
की की की की बी जी की

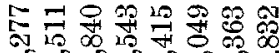

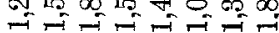

只㐘

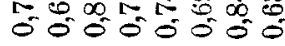

ชิ

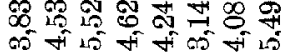

$=$ 10

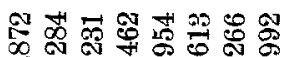
जी की कू मी की की

T

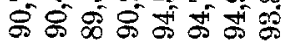

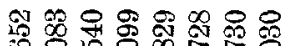
की हो की भु

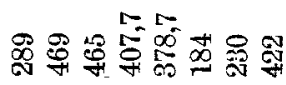

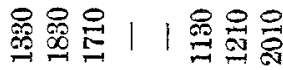

\begin{tabular}{|c|c|c|}
\hline$-i \infty$ & 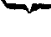 & ف \\
\hline$\sum_{Z}^{\Phi} \frac{\infty}{d}$ & 总 & 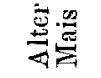 \\
\hline
\end{tabular}




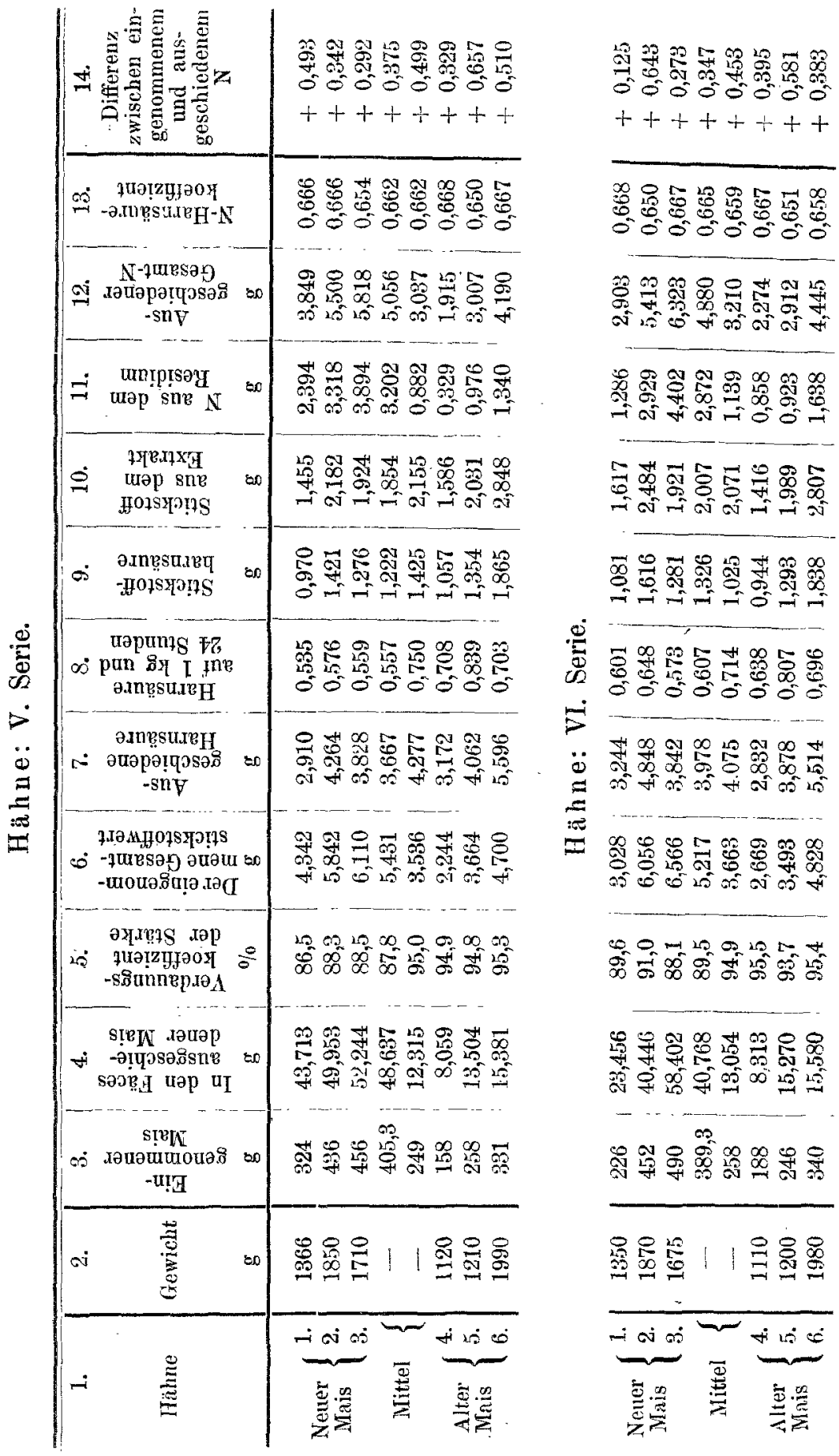




\begin{tabular}{|c|c|}
\hline 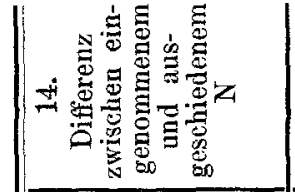 & 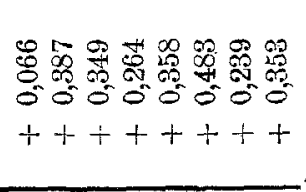 \\
\hline 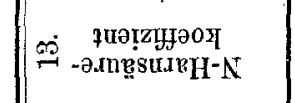 & 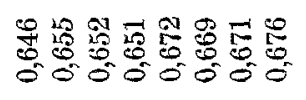 \\
\hline 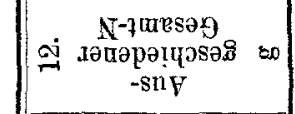 & 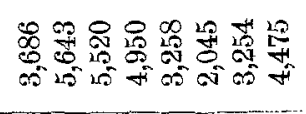 \\
\hline 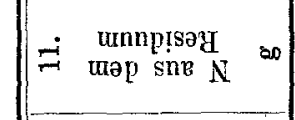 & 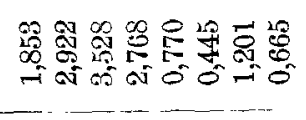 \\
\hline 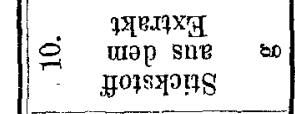 & 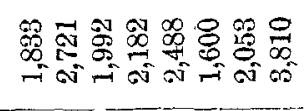 \\
\hline 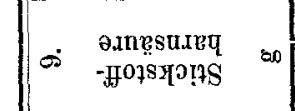 & 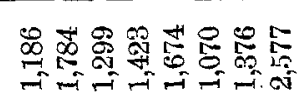 \\
\hline 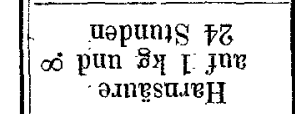 & 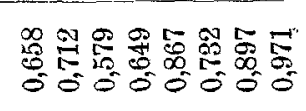 \\
\hline 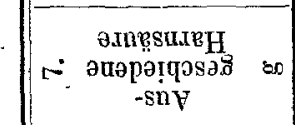 & 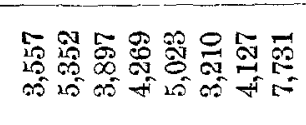 \\
\hline 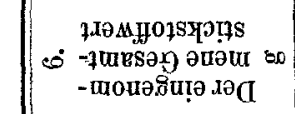 & 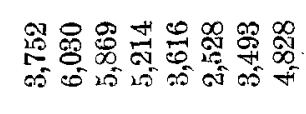 \\
\hline 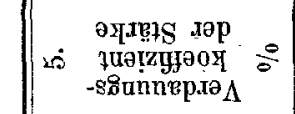 & 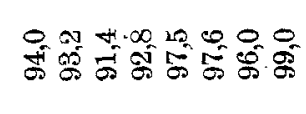 \\
\hline 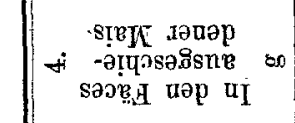 & 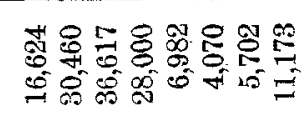 \\
\hline 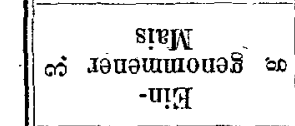 & 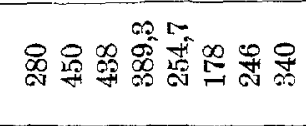 \\
\hline : & 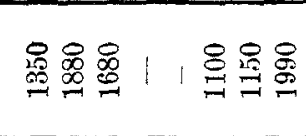 \\
\hline$\underset{\Xi}{\stackrel{\Xi}{\Xi}}$ & 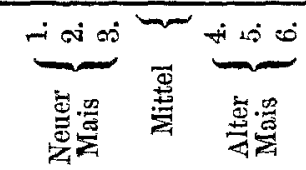 \\
\hline
\end{tabular}

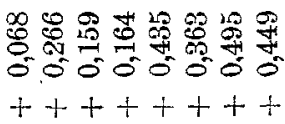

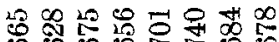
今000

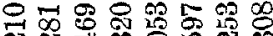
की

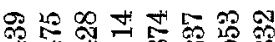
अं

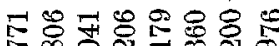

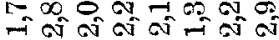

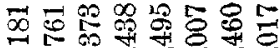
ती

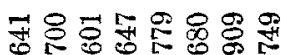

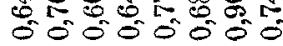

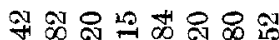
स⿺ 의

कर 20 से सं सं की सं की

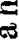

$\infty$ 둥 जी

$\Rightarrow+4, \infty 000$ ने बें क

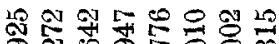
से 200000

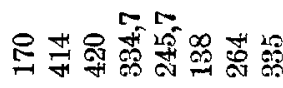

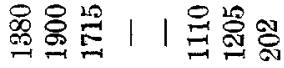

\begin{tabular}{|c|c|c|}
\hline نه & $\underbrace{-1}$ & $\dot{A} 420^{\circ}$ \\
\hline 竧: & 焉 & 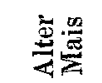 \\
\hline
\end{tabular}




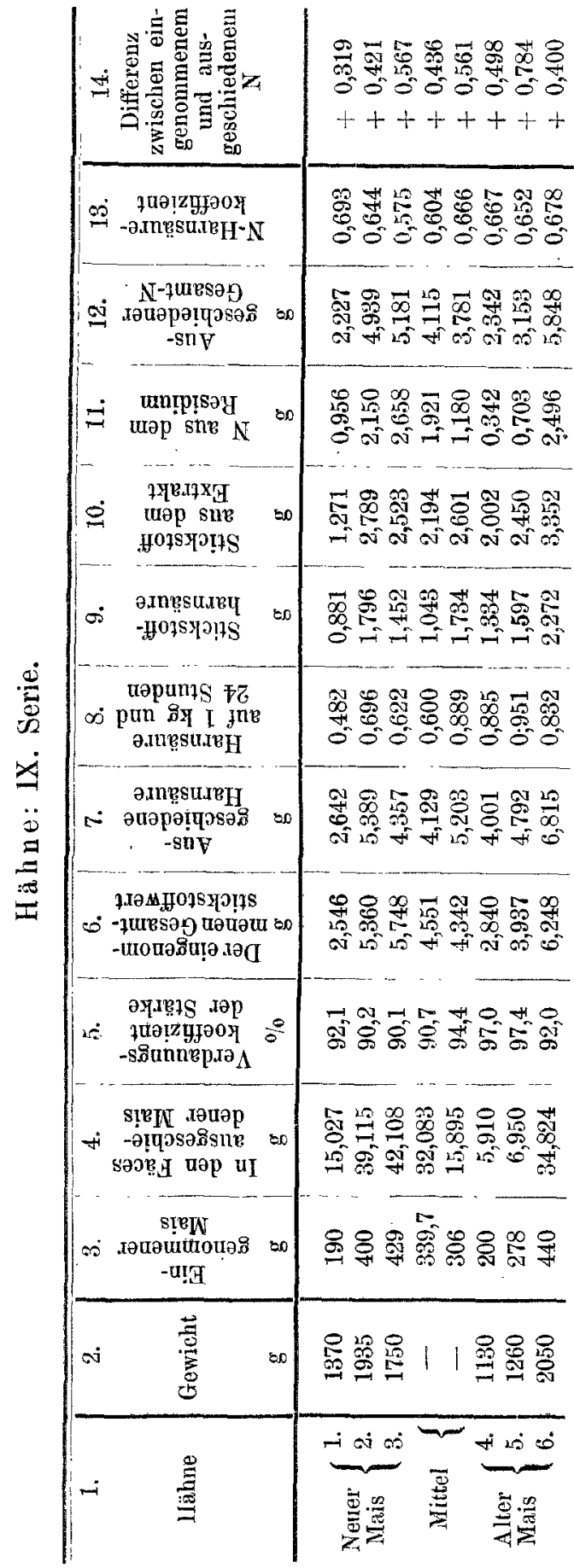

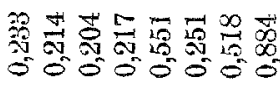
$+t+t+t+$

응

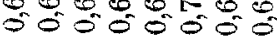

คู सं की एक की नी की

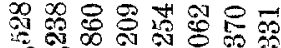
की मी मी की

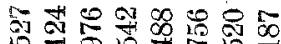
तो की की की की

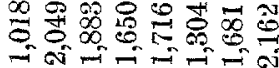

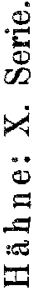

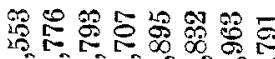

की

19 की 10 से 200 की

\% पी $\infty$ की की की को मे

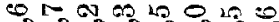

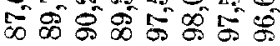

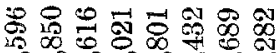

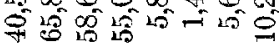

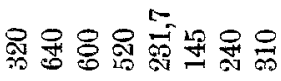

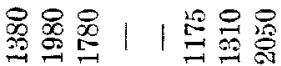

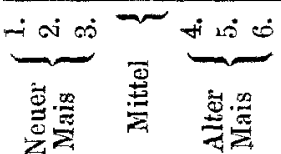




\begin{tabular}{|c|c|c|c|}
\hline 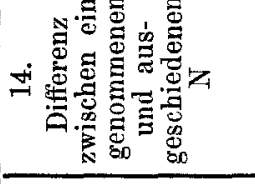 & 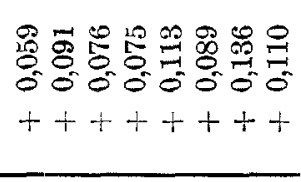 & & 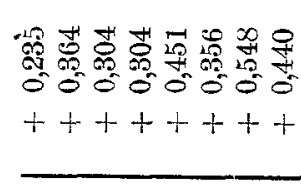 \\
\hline 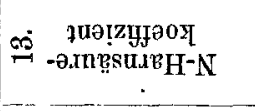 & 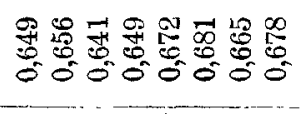 & & 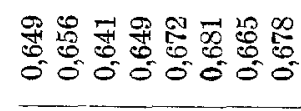 \\
\hline 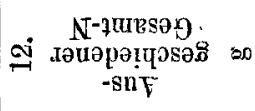 & 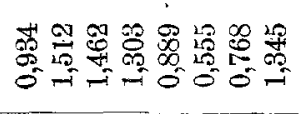 & & 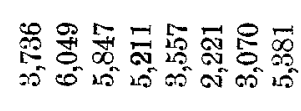 \\
\hline 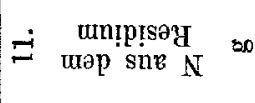 & 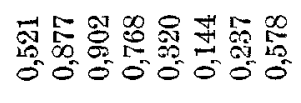 & & 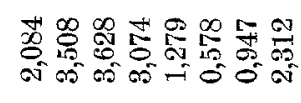 \\
\hline 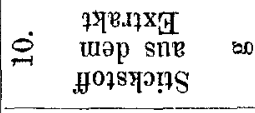 & 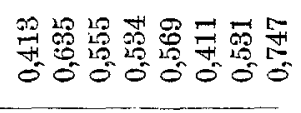 & 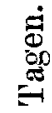 & 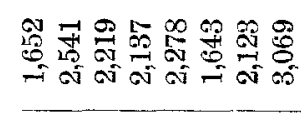 \\
\hline 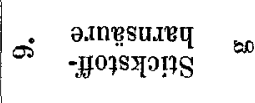 & 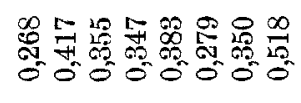 & $\stackrel{8}{\overrightarrow{0}}$ & 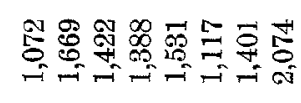 \\
\hline 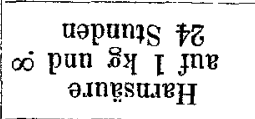 & 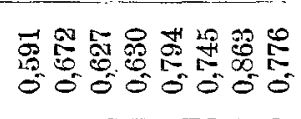 & $\stackrel{\substack{0 \\
0}}{0}$ & 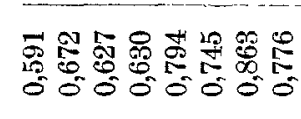 \\
\hline 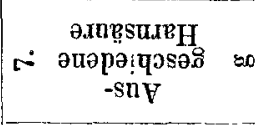 & 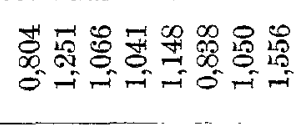 & 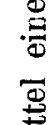 & 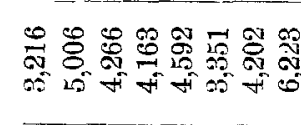 \\
\hline 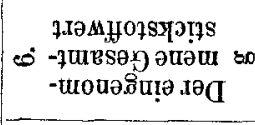 & 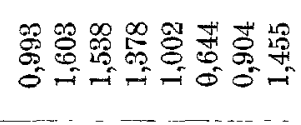 & 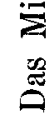 & 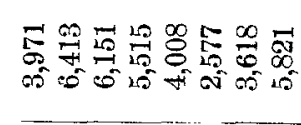 \\
\hline 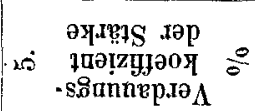 & 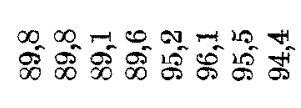 & $\ddot{\ddot{g}}$ & 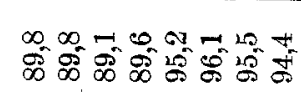 \\
\hline 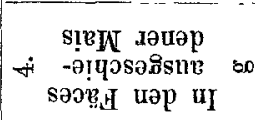 & 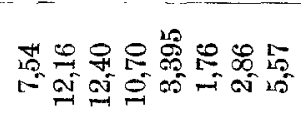 & & 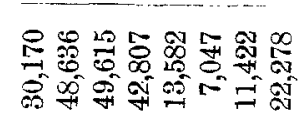 \\
\hline 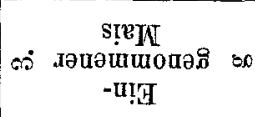 & 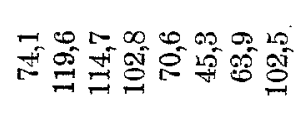 & & 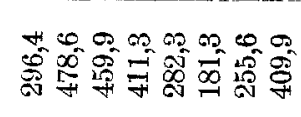 \\
\hline 小 & 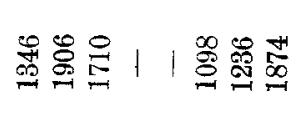 & & 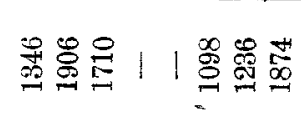 \\
\hline$\stackrel{\Xi}{\Xi}$ & 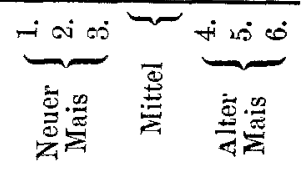 & & 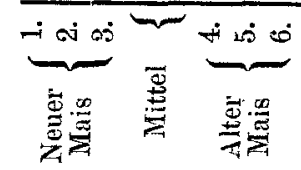 \\
\hline
\end{tabular}


Hähne: Die Mittelwerte der 29. Oktober 1912 bis

\begin{tabular}{|c|c|c|c|c|c|c|c|c|c|c|}
\hline 1. & 2. & 3. & 4. & 5. & 6. & 7. & 8. & 9. & 10. & 11 , \\
\hline \multirow[t]{2}{*}{ Hähne } & \multicolumn{2}{|c|}{$\begin{array}{l}\text { I. Serie } \\
\text { Mais }\end{array}$} & \multicolumn{2}{|c|}{$\begin{array}{l}\text { II. Serie } \\
\text { Mais }\end{array}$} & \multicolumn{2}{|c|}{$\begin{array}{l}\text { III. Serie } \\
\text { Mais }\end{array}$} & \multicolumn{2}{|c|}{$\begin{array}{c}\text { IV. Serie } \\
\text { Mais }\end{array}$} & \multicolumn{2}{|c|}{$\begin{array}{c}\text { V. Serie } \\
\text { Mais }\end{array}$} \\
\hline & $\mathrm{Neu}$ & Alt & Neu & Alt & Neu & Alt & Neu & Alt & Neu & Alt \\
\hline $\begin{array}{l}\text { Eingenomme- } \\
\text { ner Mais in } \\
\text { Gramm. . . }\end{array}$ & 488,3 & 320 & 429,3 & 325 & 409,7 & 354 & 407,7 & 387,7 & 405,3 & 249 \\
\hline $\begin{array}{l}\text { Ausgeschiede- } \\
\text { ner Mais in } \\
\text { Gramm... }\end{array}$ & 56,438 & 17,191 & 42,949 & 14,707 & 40,457 & 21,264 & 42,058 & 15,829 & 48,637 & 12,315 \\
\hline $\begin{array}{l}\text { Verdauungs- } \\
\text { koeffizient } \\
\text { der Stärke . }\end{array}$ & 88,5 & 94,6 & 90,0 & 95,5 & 90,1 & 94,3 & 90,2 & 94,5 & 87,8 & 95,0 \\
\hline $\begin{array}{l}\text { Eingenomme- } \\
\text { ner Gesamt- } \\
\text { stickstof in } \\
\text { Gramm. . }\end{array}$ & 6,544 & 4,544 & 5,691 & 4,615 & 5,489 & 5,027 & 5,462 & 3,957 & 5,431 & 3,536 \\
\hline $\begin{array}{l}\text { Gesamte aus- } \\
\text { geschiedene } \\
\text { Harnsäure }\end{array}$ & 3,894 & 4,121 & 3,835 & 4,498 & 3,961 & 4,846 & 4,628 & 4,244 & 3,667 & 4,277 \\
\hline $\begin{array}{l}\text { Harnsäure auf } \\
1 \mathrm{~kg} \text { und } 24 \\
\text { Stunden }\end{array}$ & 0,598 & 0,752 & 0,603 & 0,771 & 0,612 & 0,823 & 0,715 & 0,741 & 0,557 & 0,750 \\
\hline $\begin{array}{l}\text { Der N der } \\
\text { Harnsäure in } \\
\text { Gramm. }\end{array}$ & 1,298 & 1,374 & 1,278 & 1,499 & 1,320 & 1,615 & 1,543 & 1,415 & 1,222 & 1,425 \\
\hline $\begin{array}{l}\text { Der Gesamt- } \\
\text { stickstoffwert } \\
\text { aus dem Ex- } \\
\text { trakte in } \\
\text { Gramm... }\end{array}$ & 2,070 & 2,026 & 1,964 & 2,210 & 2,014 & 2,464 & 2,405 & 2,103 & 1,854 & 2,155 \\
\hline $\begin{array}{l}\text { Gesamtstick- } \\
\text { stoffwert aus } \\
\text { dem Residuum } \\
\text { in Gramm . }\end{array}$ & 4,183 & 2,304 & 3,494 & 1,932 & 3,217 & 2,216 & 2,722 & 1,471 & 3,202 & 0,882 \\
\hline $\begin{array}{l}\text { Dex gesamte } \\
\text { ausgeschie- } \\
\text { dene Stick- } \\
\text { stoff i. Gramm }\end{array}$ & 6,253 & 4,329 & 5,458 & 4,142 & 5,231 & 4,680 & 5,127 & 3,573 & 5,056 & 3,087 \\
\hline $\begin{array}{l}\text { Der Stickstoff- } \\
\text { harnsäure- } \\
\text { koeffizient }\end{array}$ & 0,623 & 0,675 & 0,648 & 0,680 & 0,655 & 0,654 & 0,641 & 0,669 & 0,662 & 0,662 \\
\hline $\begin{array}{l}\text { Differenz zwi- } \\
\text { schen einge- } \\
\text { nommenem } \\
\text { und ausge- } \\
\text { schiedenem } \\
\text { Stickstoff . }\end{array}$ & $+0,291$ & $+0,215$ & $+0,283$ & $+0,473$ & $+0,258$ & $+0,347$ & $1+0,935$ & $+0,384$ & $+0,375$ & $+0,499$ \\
\hline
\end{tabular}


10 Serien (jede Serie von 4 Tagen).

8. Dezember 1912.

\begin{tabular}{|c|c|c|c|c|c|c|c|c|c|c|c|}
\hline 12. & 18. & 14. & 15. & 16. & 17. & 18. & 19. & 20. & 21. & 22. & 23. \\
\hline \multicolumn{2}{|c|}{$\begin{array}{c}\text { VI. Serie } \\
\text { Mais }\end{array}$} & \multicolumn{2}{|c|}{$\begin{array}{c}\text { VII. Serie } \\
\text { Mais }\end{array}$} & \multicolumn{2}{|c|}{$\begin{array}{c}\text { VIII. Serie } \\
\text { Nais }\end{array}$} & \multicolumn{2}{|c|}{$\begin{array}{c}\text { IX. Serie } \\
\text { Mais }\end{array}$} & \multicolumn{2}{|c|}{$\begin{array}{c}\text { X. Serie } \\
\text { Mais }\end{array}$} & \multicolumn{2}{|c|}{ Mais } \\
\hline Neu & Alt & Neu & Alt & Neu & Alt & Neu & Alt & Neu & Alt & Neu & Alt \\
\hline 389,3 & 258 & 389,3 & 254,7 & 339,7 & 245,7 & 339,7 & 306 & 520 & 231,7 & 412,08 & 293,18 \\
\hline 40,768 & 13,054 & 28,00 & 6,982 & 38,947 & 12,776 & 32,088 & 15,895 & 55,021 & 5,801 & 42,5355 & 13,581 \\
\hline 89,5 & 94,9 & 92,8 & 97,5 & 88,8 & 95,0 & 90,7 & 94,4 & 89,3 & 97,5 & 89,8 & 95,4 \\
\hline 5,217 & 3,663 & 5,214 & 3,616 & 4,484 & 3,488 & 4,551 & 4,342 & 6,968 & 3,293 & 5,505 & 4,008 \\
\hline 3,978 & 4,075 & 4,269 & 5,028 & 4,315 & 4,484 & 4,129 & 5,203 & 4,950 & $\tilde{5}, 147$ & 4,163 & 4,592 \\
\hline 0,607 & 0,714 & 0,649 & 0,867 & 0,647 & 0,779 & 0,600 & 0,889 & 0,707 & 0,895 & 0,629 & 0,796 \\
\hline 1,326 & 1,025 & 1,428 & 1,674 & 1,438 & 1,495 & 1,043 & 1,734 & 1,650 & 1,716 & 1,354 & 1,497 \\
\hline 2,007 & 2,071 & 2,182 & 2,488 & 2,206 & 2,179 & 2,194 & 2,601 & 2,542 & 2,488 & 2,144 & 2,278 \\
\hline 2,872 & 1,139 & 2,768 & 0,770 & 2,114 & 0,874 & 1,921 & 1,180 & 4,209 & 0,254 & 4,070 & 1,302 \\
\hline 4,880 & 3,210 & 4,950 & 3,258 & 4,320 & 3,286 & 4,115 & 3,781 & 6,751 & 2,742 & 5,214 & 3,604 \\
\hline 0,665 & 0,659 & 0,651 & 0,672 & 0,656 & 0,701 & 0,604 & 0,666 & 0,650 & 0,700 & 0,645 & 0,673 \\
\hline$+0,347$ & $+0,453$ & $+0,264$ & $=0,358$ & $+0,164 \mid$ & $+0,435$ & $+0,436$ & $+0,561$ & $+0,217$ & $+0,551$ & $+0,302$ & $+0,371$ \\
\hline
\end{tabular}




\begin{tabular}{|c|c|c|}
\hline & 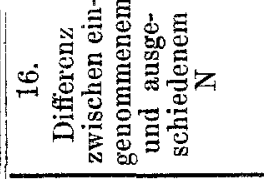 & 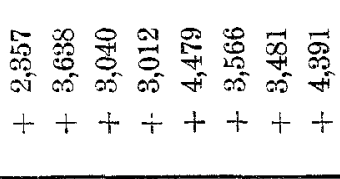 \\
\hline$\sum_{\substack{0 \\
0=1}}^{0}$ & 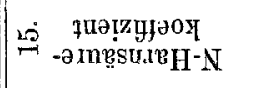 & 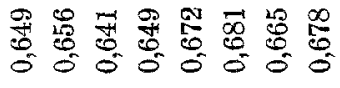 \\
\hline$\sum_{0}^{\infty}$ & 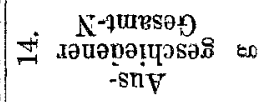 & 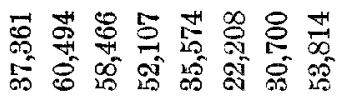 \\
\hline : & $\stackrel{\text { unnpysay }}{2}$ & 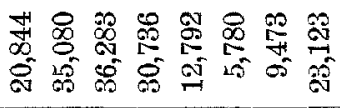 \\
\hline 赔 & 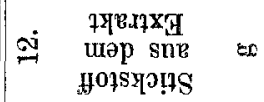 & 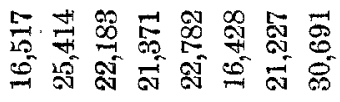 \\
\hline बi & $\Longrightarrow \begin{array}{ll}\text { amnessurgu } \\
\text {-Hoisyo!ns }\end{array}$ & 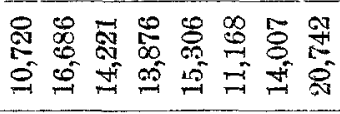 \\
\hline 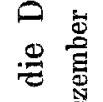 & 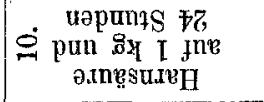 & 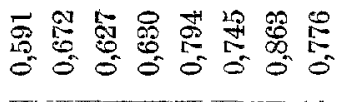 \\
\hline $\begin{array}{ll}\Xi & 0 \\
0 & \infty \\
\infty & \infty \\
0 & \infty\end{array}$ & 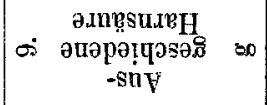 & 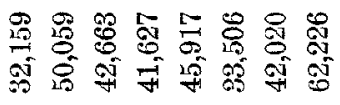 \\
\hline 总昜 & 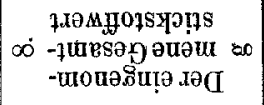 & 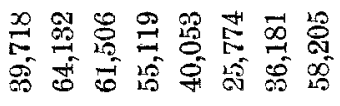 \\
\hline 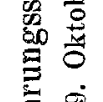 & 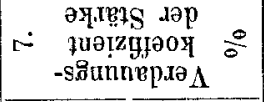 & 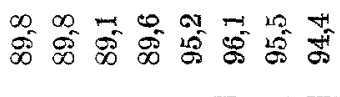 \\
\hline 胥 & 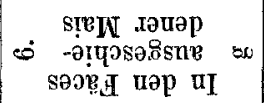 & 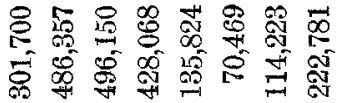 \\
\hline$\frac{D}{g}$ & 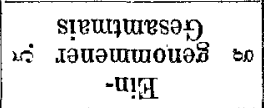 & 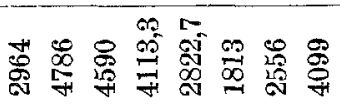 \\
\hline 률 & 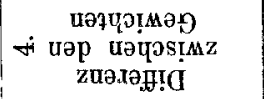 & 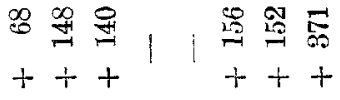 \\
\hline & 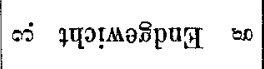 & 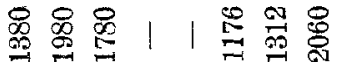 \\
\hline$\equiv$ & 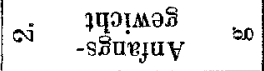 & 帚总 \\
\hline & $\stackrel{\Xi}{\Xi}$ & 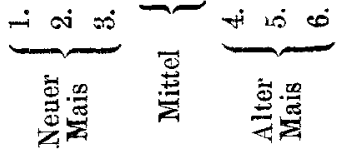 \\
\hline
\end{tabular}


Als Kontrolle haben wir nebenstehend zwei Nahrungsstoffwechseltabellen, die an der Henne und am Hahne experimentiert wurden, welche nach Kossa an Annus praeternaturalis operiert wurden und somit der Harn separat von den Fäces aufgefangen wurde.

In diesen Tabellen sehen wir, dass die Ziffer der Harnsäure auf $1 \mathrm{~kg}$ und 24 Stunden siç der von den früheren Tabellen nähert; dass das Verhältnis $\frac{N-\text { Harnsäure }}{N-\text { Harn }}$ (Harnstickstoffkoeffizient) einen Wert ergibt, der den Ziffern von den Tabelien, wo dieser Koeffizient aus dem Verhältnis N-Harnsäure $\mathrm{Nd}$ d.Extrakts m.Li(OH) auffindbar ist, sich ebenfalls beträchtlich nähert.

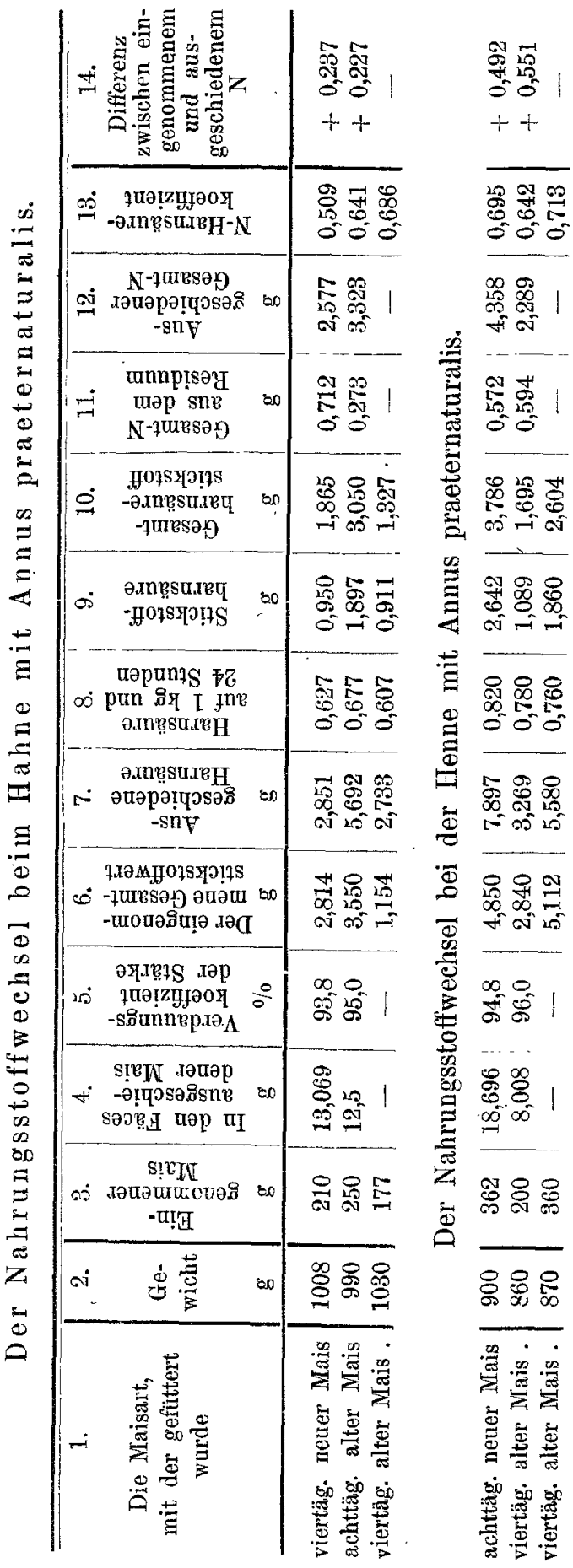


C. Die Experimente an weissen Ratten.

Das dritte Experiment wurde an weissen Ratten gemacht, ebenfalls sechs an der Zahl, drei in der einen Gruppe und drei in der zweiten. Die erste Reihe wurde mit Mais aus der neuen Ernte - 1913 -, die zweite Gruppe mit Mais von gleichem Alter wie der von Hähnen gefüttert.

Das Experiment hat am 22. Oktober 1913 begonnen und bis zum 25. Dezember 1913 gedauert. Auch in dieser Gruppe haben wir grosse und kräftige Ratten gehabt.

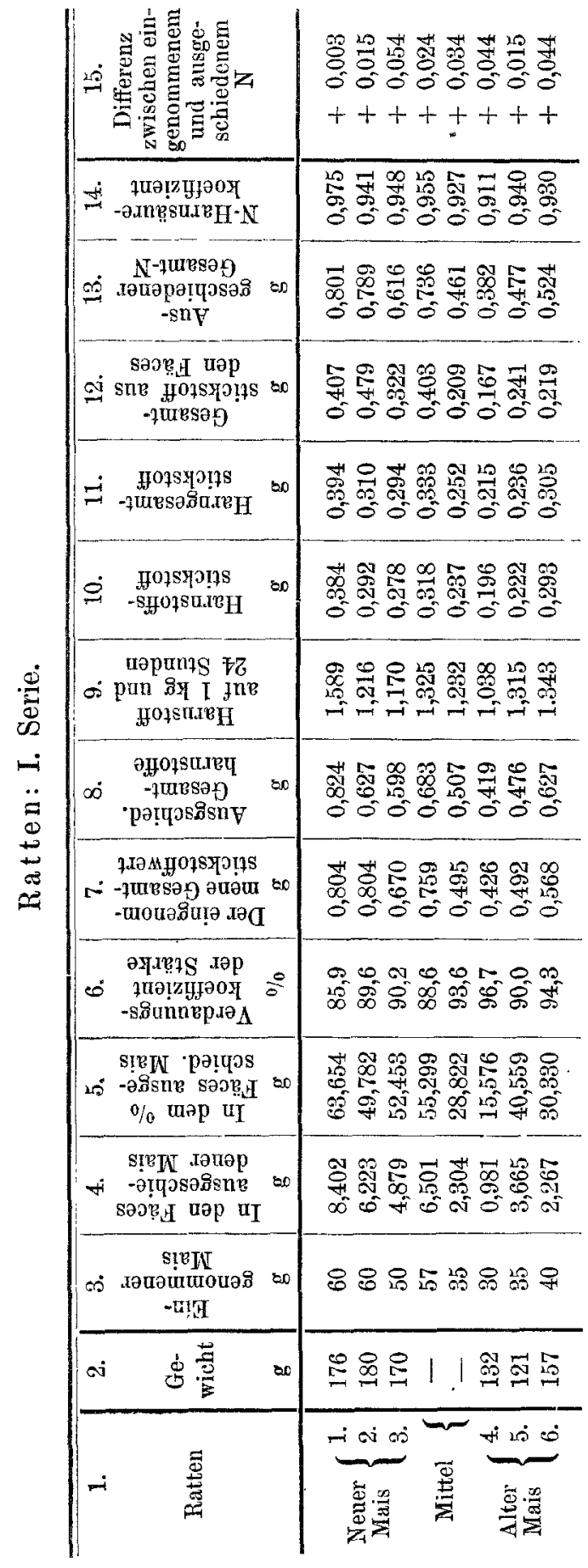




\begin{tabular}{|c|c|}
\hline 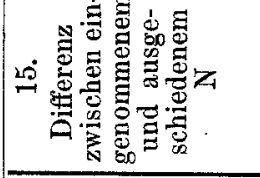 & 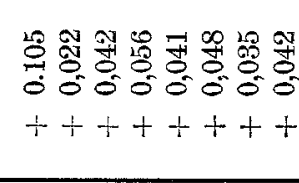 \\
\hline 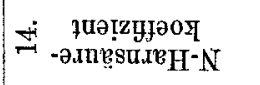 & 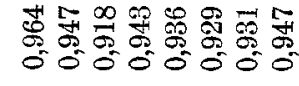 \\
\hline 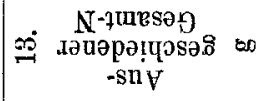 & 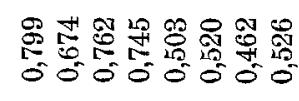 \\
\hline 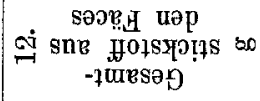 & 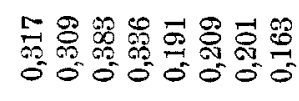 \\
\hline 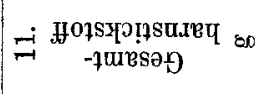 & 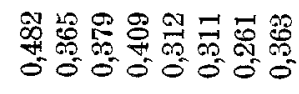 \\
\hline 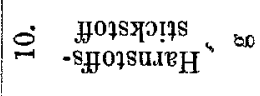 & 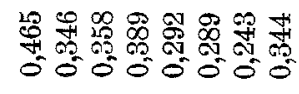 \\
\hline 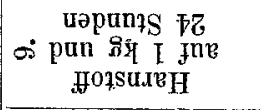 & 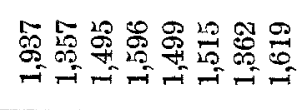 \\
\hline 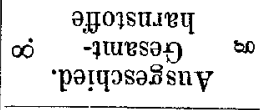 & 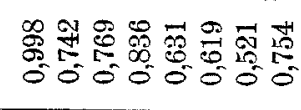 \\
\hline 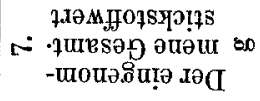 & 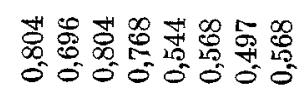 \\
\hline 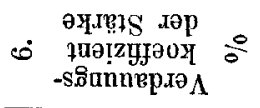 & क \\
\hline 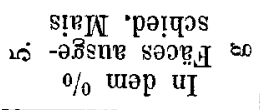 & 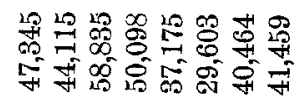 \\
\hline 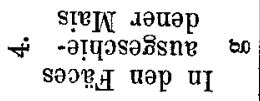 & $\begin{array}{l}\infty \\
\oint\end{array}$ \\
\hline 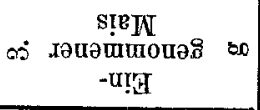 & 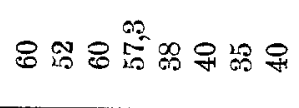 \\
\hline dُ & 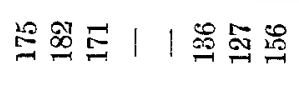 \\
\hline 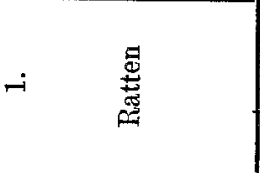 & 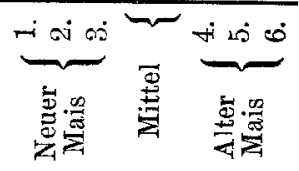 \\
\hline
\end{tabular}

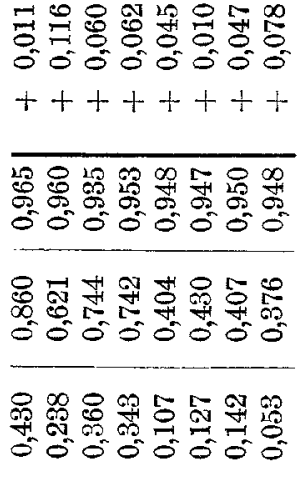

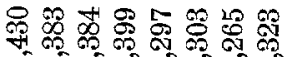

Н

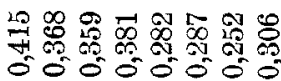

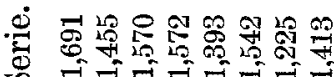

영

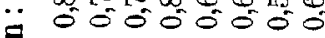

0

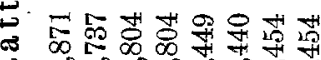

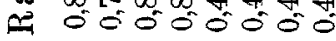

न

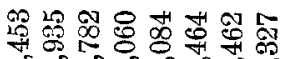

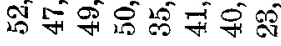

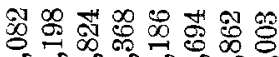

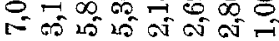

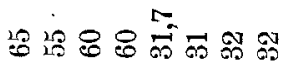

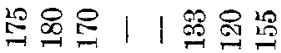

\begin{tabular}{|c|c|c|}
\hline ڤه نه & $\underbrace{-m}$ & ن \\
\hline 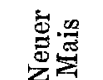 & 要 & 总量 \\
\hline
\end{tabular}




\begin{tabular}{|c|c|c|c|}
\hline 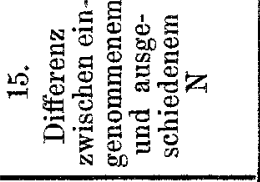 & 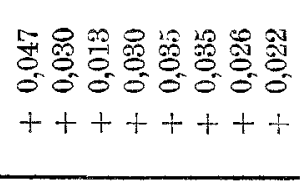 & & 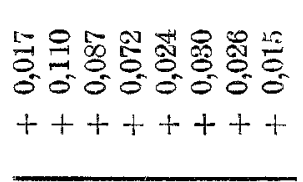 \\
\hline 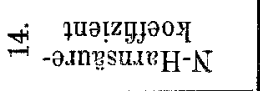 & 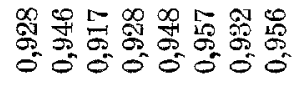 & & 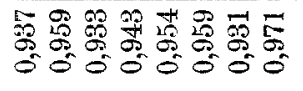 \\
\hline 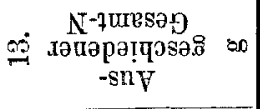 & 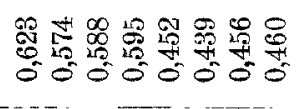 & & 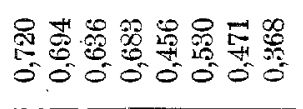 \\
\hline 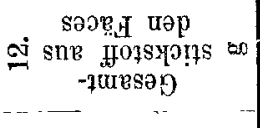 & 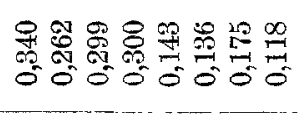 & & 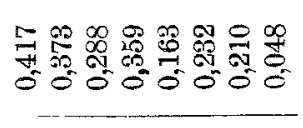 \\
\hline 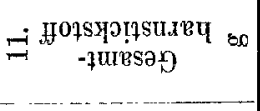 & 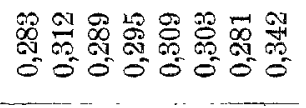 & & 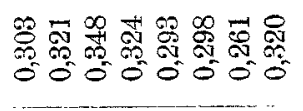 \\
\hline 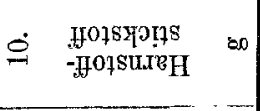 & 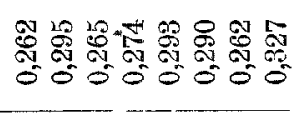 & & 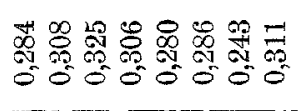 \\
\hline 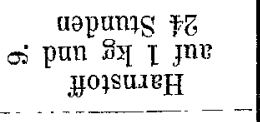 & 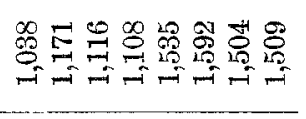 & 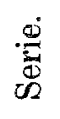 & 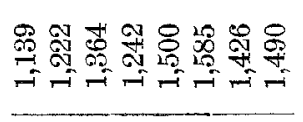 \\
\hline 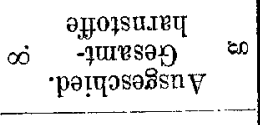 & 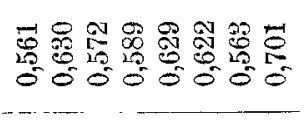 & $\ddot{\ddot{c}}$ & 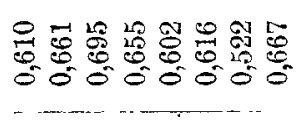 \\
\hline 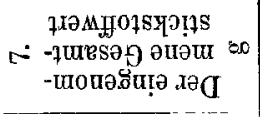 & 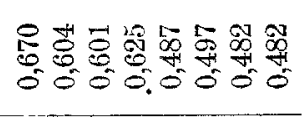 & $\underset{⿱ 亠}{\stackrel{+}{\rightleftarrows}}$ & 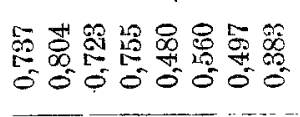 \\
\hline 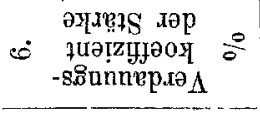 & 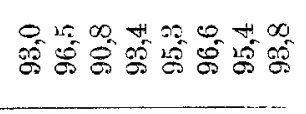 & & 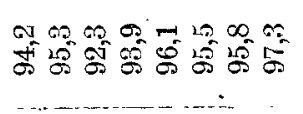 \\
\hline 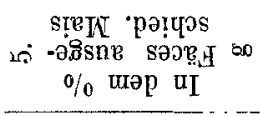 & 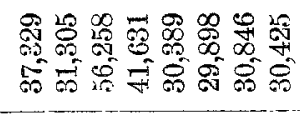 & & 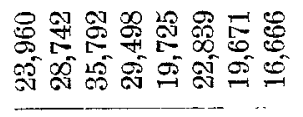 \\
\hline 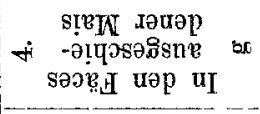 & 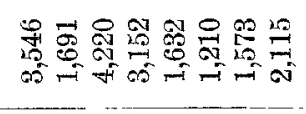 & & 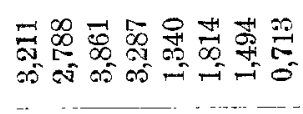 \\
\hline 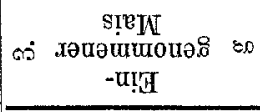 & 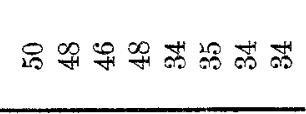 & & 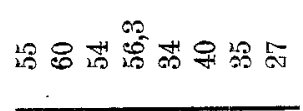 \\
\hline a $\quad \dot{0} \frac{\overrightarrow{3}}{0}$ & 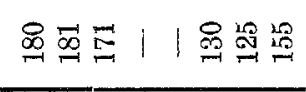 & & 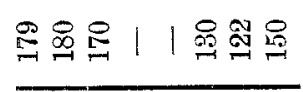 \\
\hline 莺 & 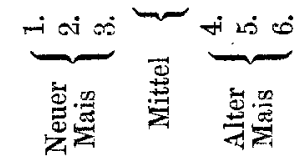 & & 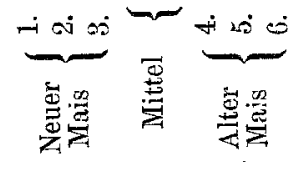 \\
\hline
\end{tabular}




\begin{tabular}{|c|c|}
\hline 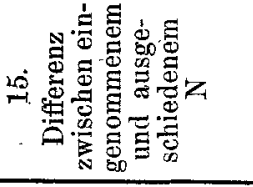 & 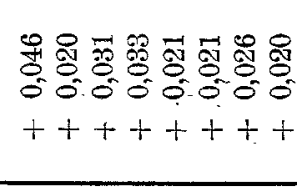 \\
\hline 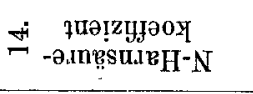 & 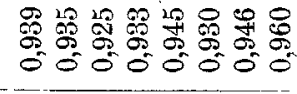 \\
\hline 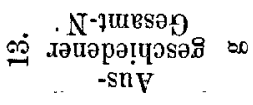 & 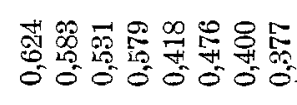 \\
\hline 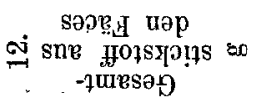 & 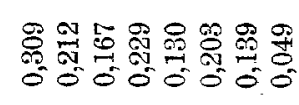 \\
\hline 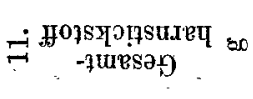 & 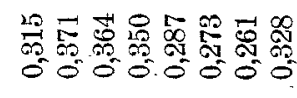 \\
\hline 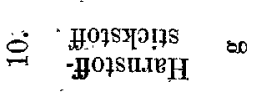 & 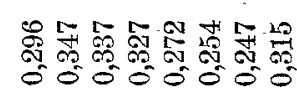 \\
\hline 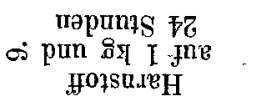 & 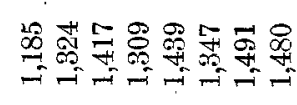 \\
\hline 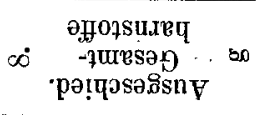 & 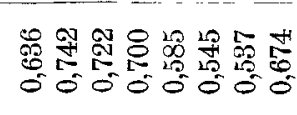 \\
\hline 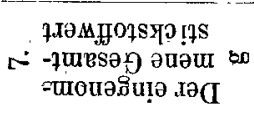 & 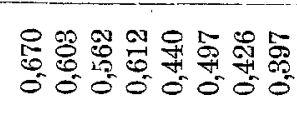 \\
\hline 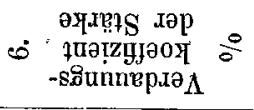 & 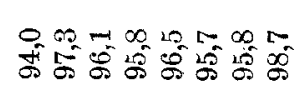 \\
\hline 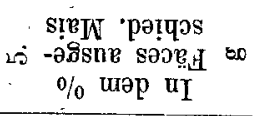 & 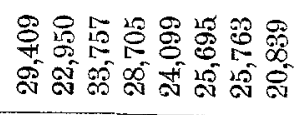 \\
\hline 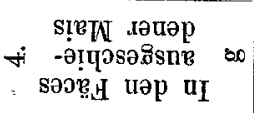 & 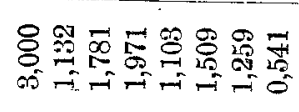 \\
\hline 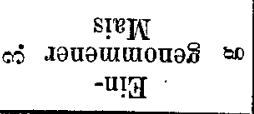 & 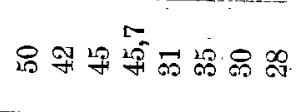 \\
\hline งi d d & 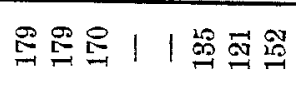 \\
\hline 耊 & 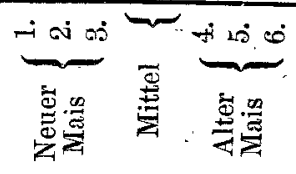 \\
\hline
\end{tabular}

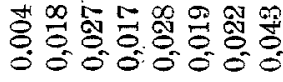
$+++t+1+t$

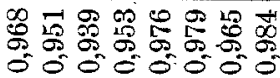

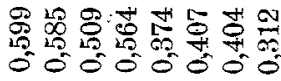

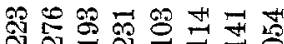

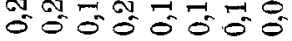

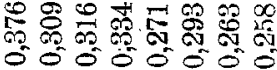

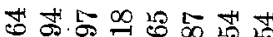
sog

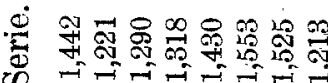

$\dot{\xi}$

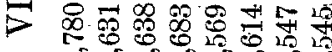

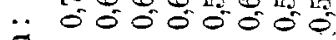

(1)

$+$

$\infty$

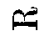

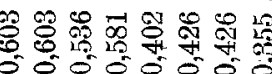

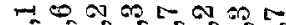

यूำ

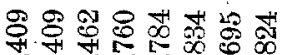

ลั

$89 \infty$

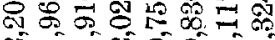

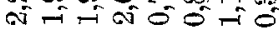

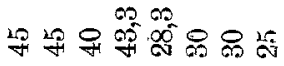

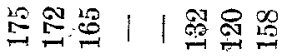

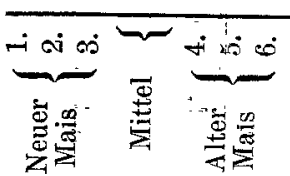




\begin{tabular}{|c|c|}
\hline 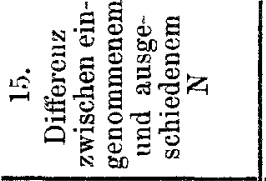 & 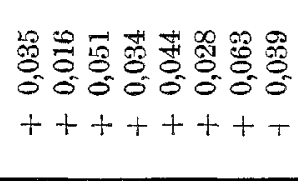 \\
\hline 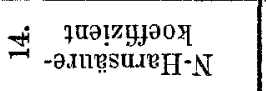 & 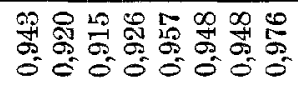 \\
\hline 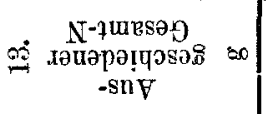 & 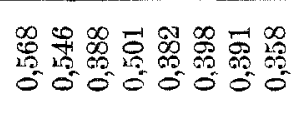 \\
\hline 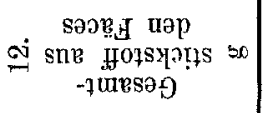 & 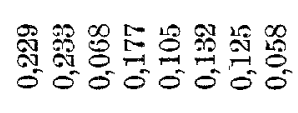 \\
\hline 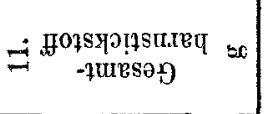 & 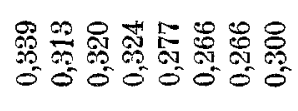 \\
\hline 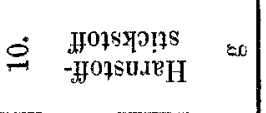 & 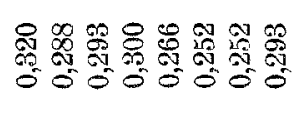 \\
\hline $\begin{array}{c}\text { uepunas } 76 \\
\text { os pun sq I yne } \\
\text { Hoisure }\end{array}$ & 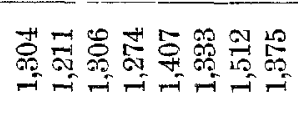 \\
\hline 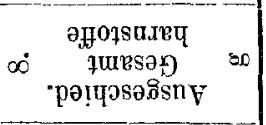 & 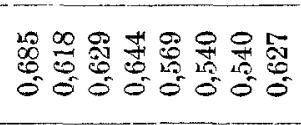 \\
\hline 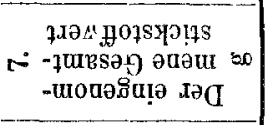 & 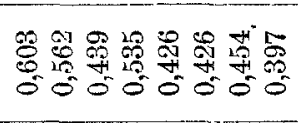 \\
\hline 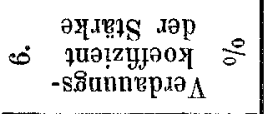 & 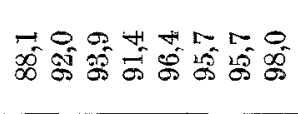 \\
\hline 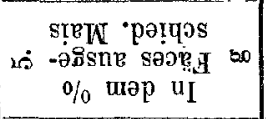 & 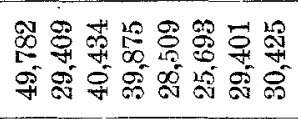 \\
\hline 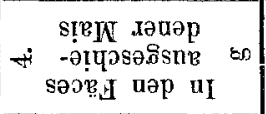 & 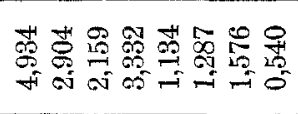 \\
\hline 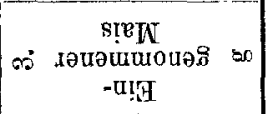 & 원 \\
\hline oi $\quad \frac{d}{0}$ & 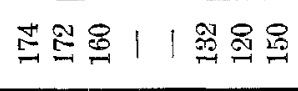 \\
\hline 焉 & 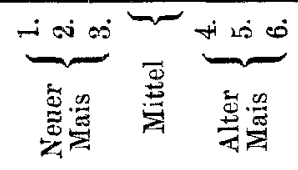 \\
\hline
\end{tabular}

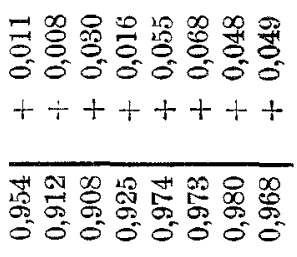

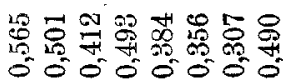

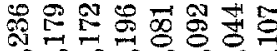

$050=0000$

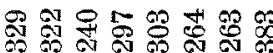

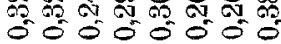

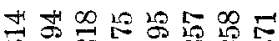

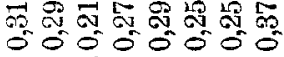

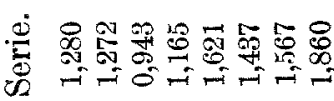

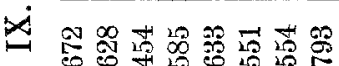

$\because 00000000$

9

$\stackrel{0}{+\infty}$

응 영영 ino 000000

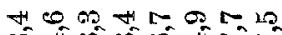
बूँ

원 월

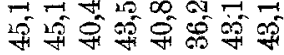

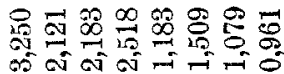

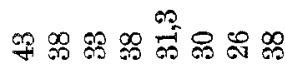

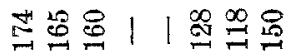

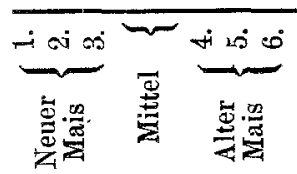




\begin{tabular}{|c|c|}
\hline 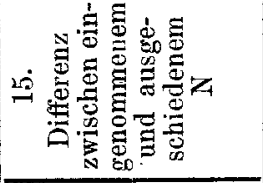 & $\begin{array}{l}+9858098 \\
88888080 \\
00050000 \\
++1+++++\end{array}$ \\
\hline 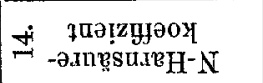 & 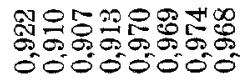 \\
\hline 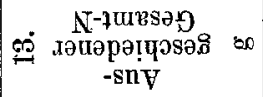 & 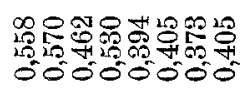 \\
\hline $\begin{array}{c}\text { səo․․ uәp } \\
\text { oi sne \#0qsyo!̣s so } \\
\text {-queseg }\end{array}$ & 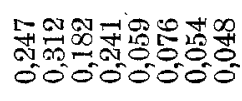 \\
\hline 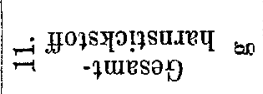 & 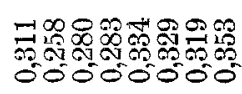 \\
\hline 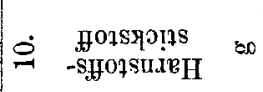 & 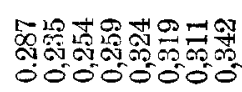 \\
\hline 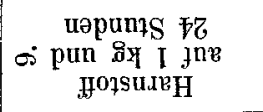 & 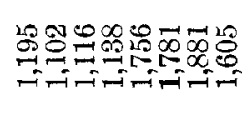 \\
\hline 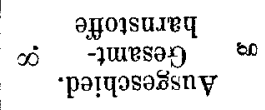 & 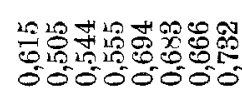 \\
\hline 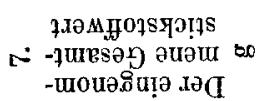 & 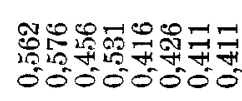 \\
\hline 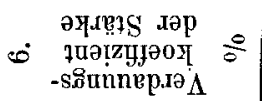 & 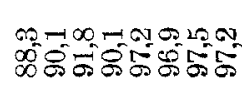 \\
\hline 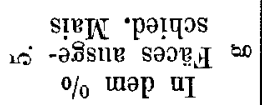 & 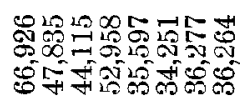 \\
\hline 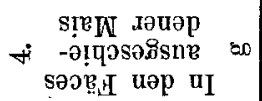 & 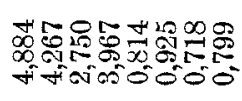 \\
\hline 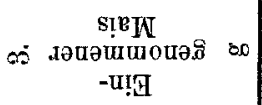 & 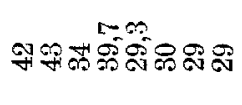 \\
\hline oi 过总 & 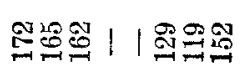 \\
\hline 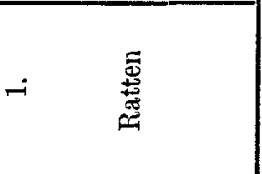 & 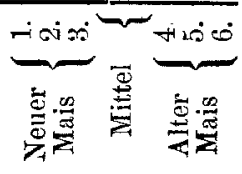 \\
\hline
\end{tabular}


Ratten: Die Mittelwerte der 22. Oktober 1913 bis

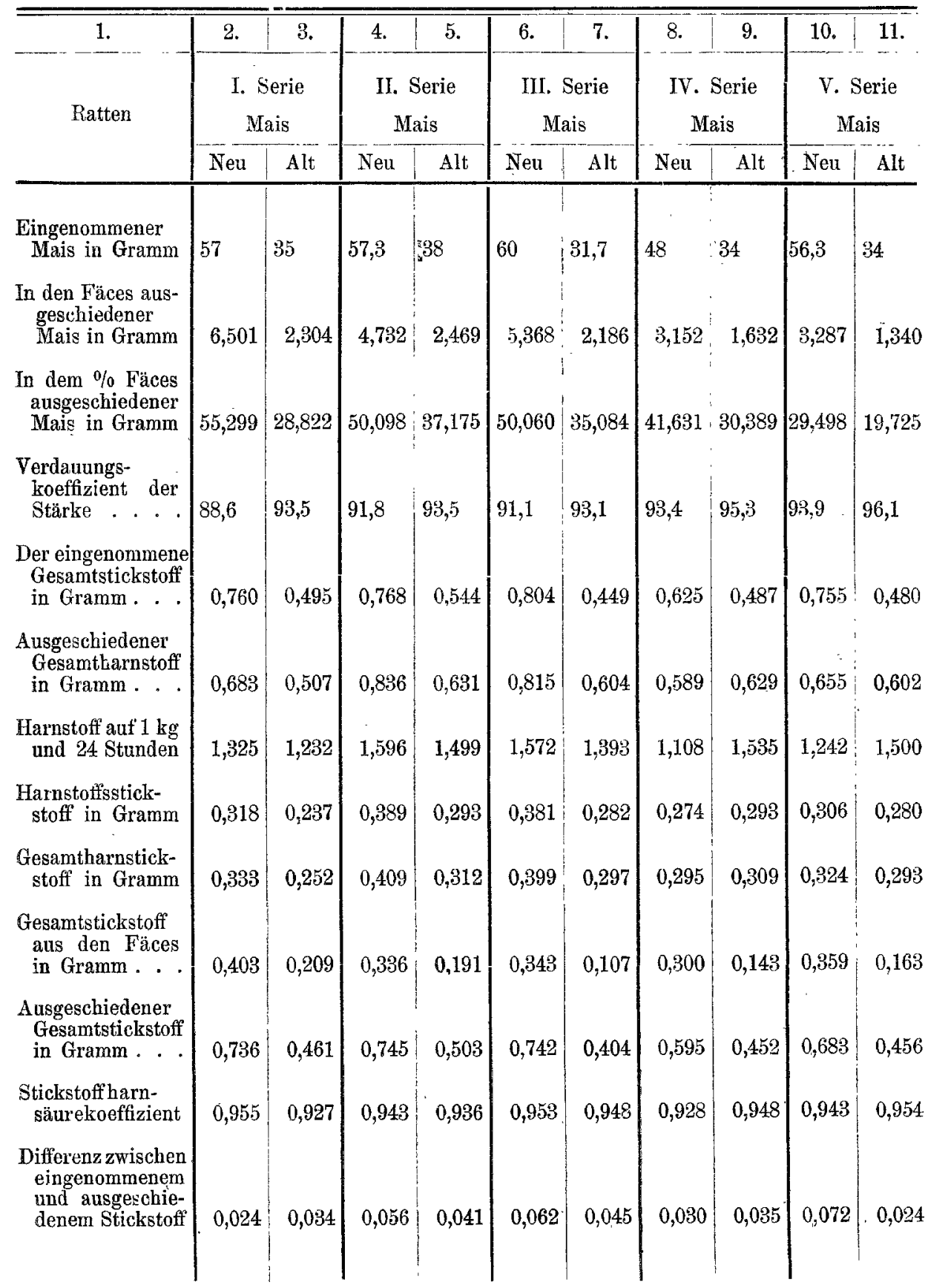


11 Serien (jede Serie von 3 Tagen).

25. November 1913.

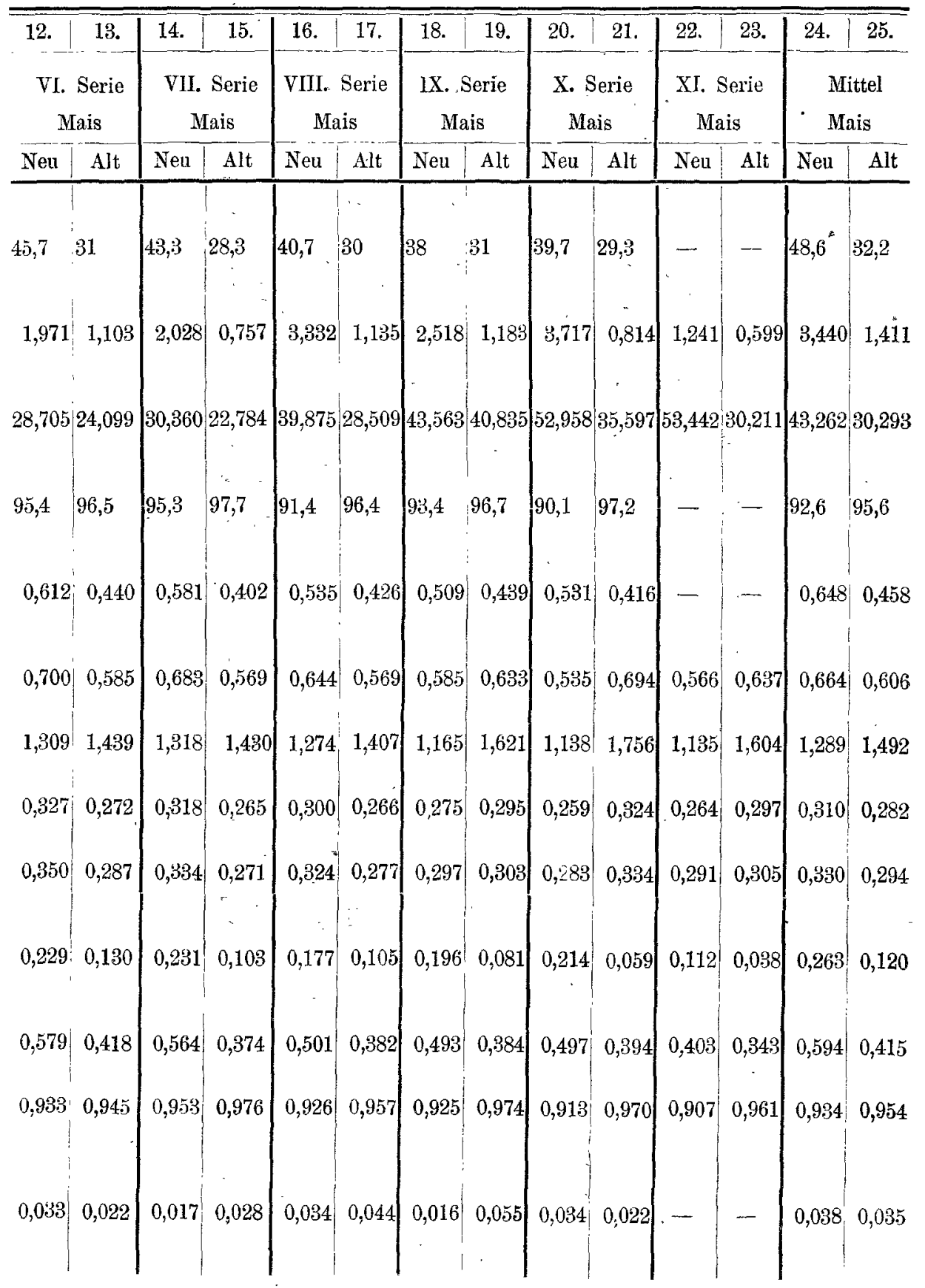




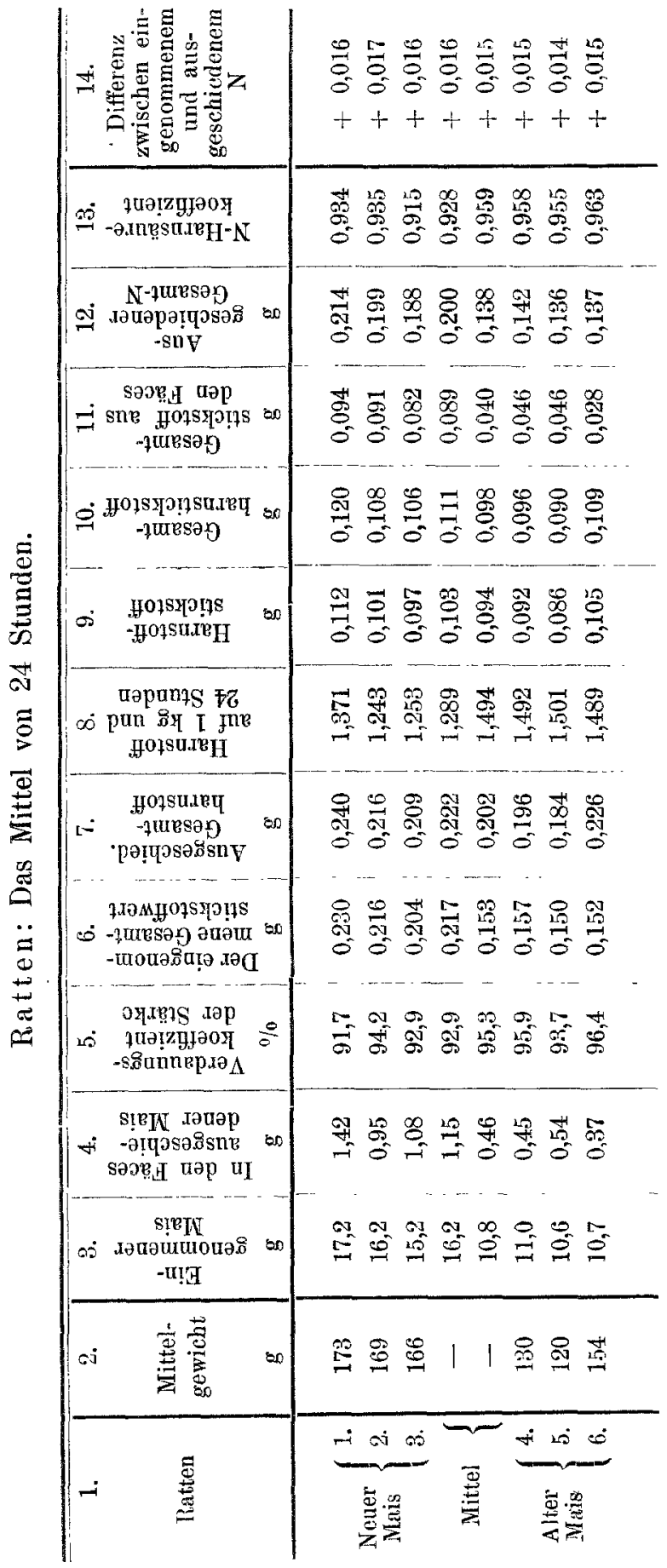


Der Nährwert des neuen und alten Maises.

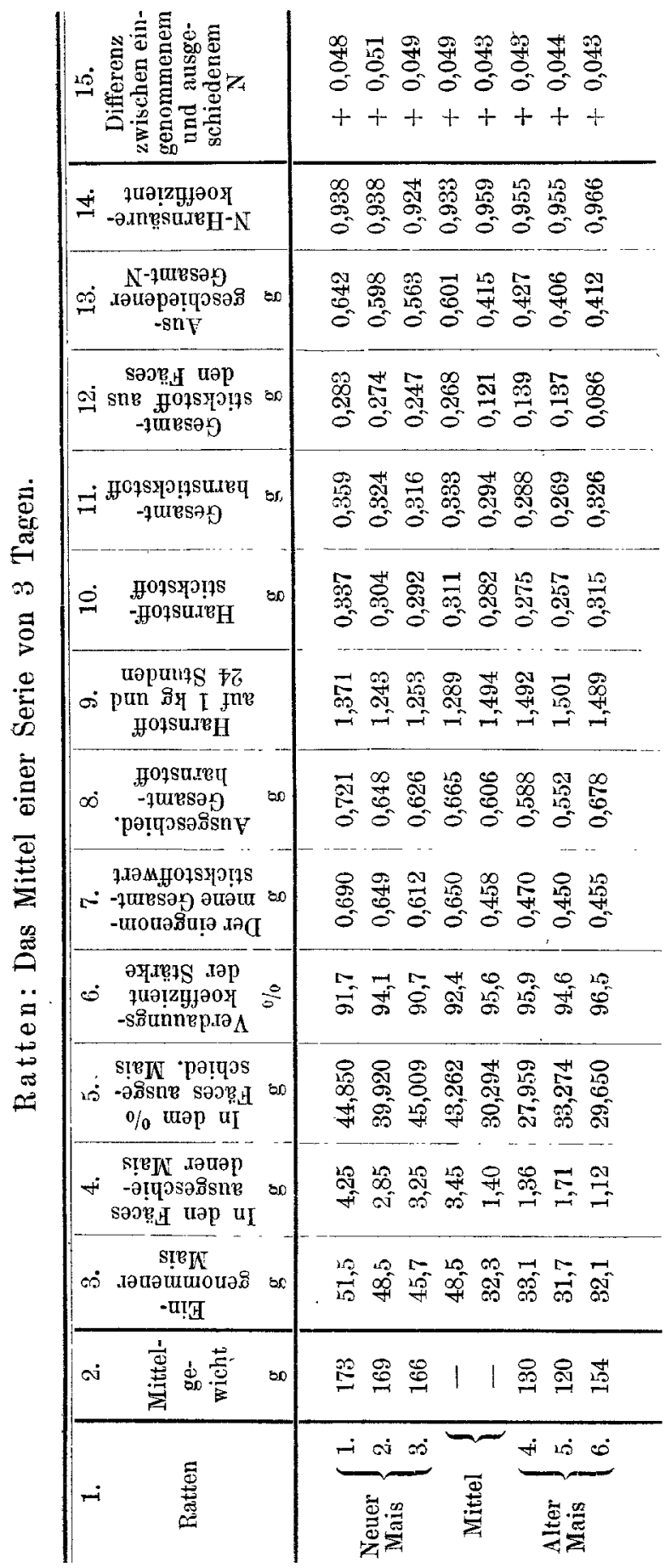




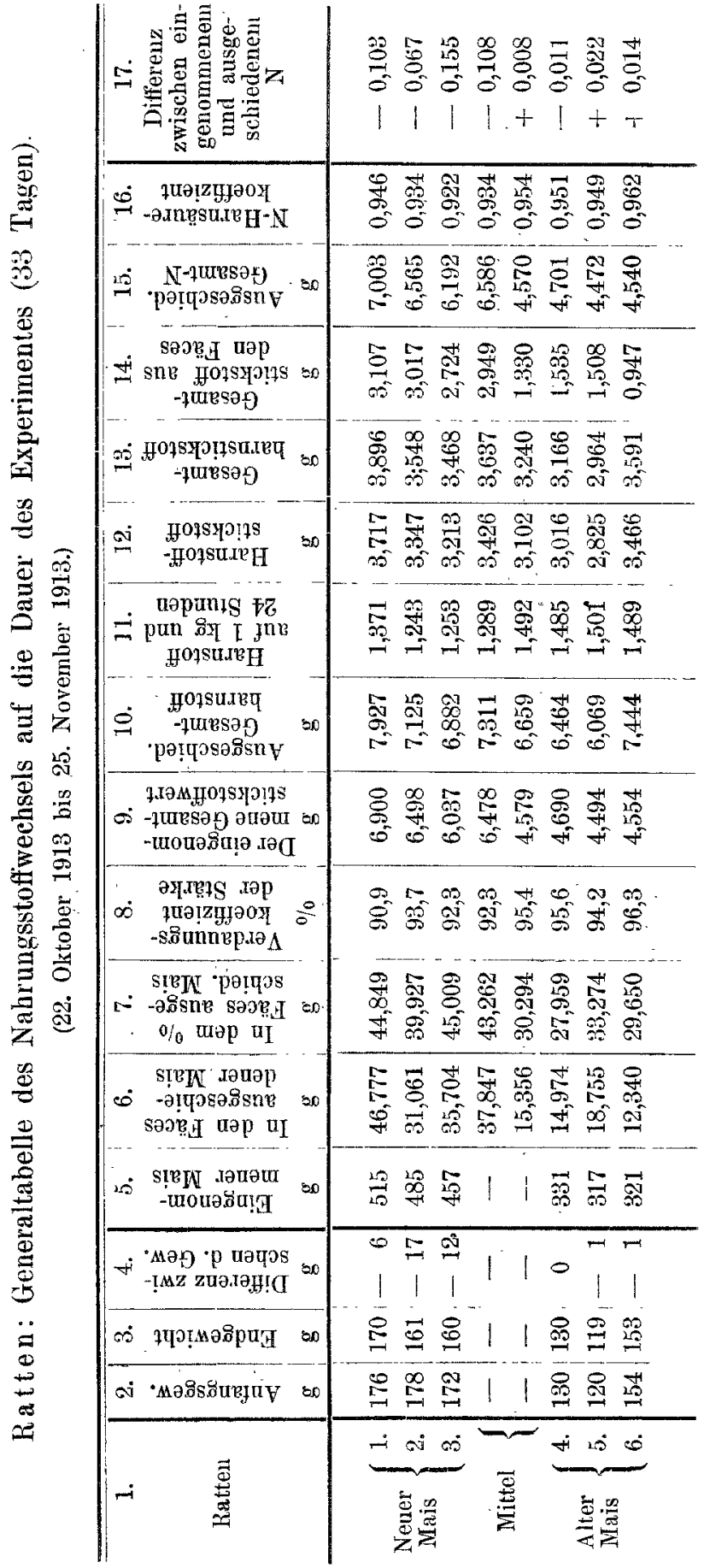




\section{Drittes Kapitel.}

\section{Die Besprechung der Resultate.}

Es ist ein näherer Blick- auf die früheren Angaben notwendig, um die notwendigen Schlussfolgerungen ziehen zu können. $\mathrm{Zu}$ dem Zwecke habe ich für jedes Experiment je eine RekapitulationsGeneral-Konsum- und -Stoffwechseltabelle während des Experiments auf $1 \mathrm{~kg}$ Gewicht des Tieres zusammengestellt.

Wir wollen nun die folgende Tabelle betrachten, welche sich auf das erste Experiment an Hühnern bezieht.

Hühner (18. Dezember 1911 bis 27. Januar 1912).

\begin{tabular}{|c|c|c|}
\hline & $\begin{array}{l}\text { I. Gruppe } \\
\text { Neuer Mais }\end{array}$ & $\begin{array}{l}\text { II. Gruppe } \\
\text { Alter . Mais }\end{array}$ \\
\hline $\begin{array}{l}\text { Eingenommener Mais auf } 1 \mathrm{~kg} \text { Gewicht des Tieres } \\
\text { während des Experiments in Gramm }\end{array}$ & 1553 & 1767 \\
\hline $\begin{array}{l}\text { Durch die Fäces ausgeschiedener Mais auf } 1 \mathrm{~kg} \\
\text { Gewicht des Tieres während des Experiments in }\end{array}$ & & \\
\hline $\begin{array}{l}\text { Gramm } \\
\text { Assimilierter } \text { Mais anf } 1 \text { kg Gewicht des Tieres in }\end{array}$ & 120 & 71 \\
\hline Gramm. . . . . . . . . . . . & 1483 & 1696 \\
\hline $\begin{array}{l}\text { Verdauungskoeffizient in Prozent . } \\
\text { Das zu Ende des Experiments gewonene oder ver- }\end{array}$ & 92 & 96 \\
\hline $\begin{array}{l}\text { Das zu Ende des Experiments gewonnene oder ver- } \\
\text { lorene Körpergewicht in Gramm }\end{array}$ & +427 & +632 \\
\hline $\begin{array}{l}\text { Der verdaute Gesamtstickstoff auf } 1 \mathrm{~kg} \text { Gewicht des } \\
\text { Tieres in Gramm } . .\end{array}$ & 22,02 & 25,09 \\
\hline 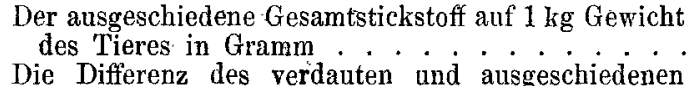 & 20,57 & 23,29 \\
\hline 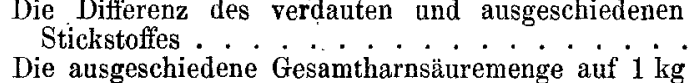 & $+1,45$ & $+1,8$ \\
\hline 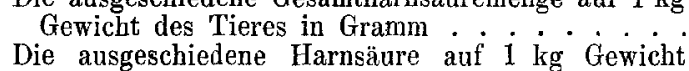 & 27,74 & 33,19 \\
\hline $\begin{array}{l}\text { während } 24 \text { Stunden in Gramm. } \\
\text { Harnstickstoffkoeffizient . }\end{array}$ & $\begin{array}{l}0,685 \\
0,608\end{array}$ & $\begin{array}{l}0,808 \\
0,6.55\end{array}$ \\
\hline
\end{tabular}

Diese Tabelle zeigt uns, dass die Ziffer des angenommenen Maises im allgemeinen unbedeutend grösser ist bei der Gruppe, die mit älterem Mais gefüttert ist, so dass der eingenommene Mais während des Experiments und auf $1 \mathrm{~kg}$ Gewicht ein Plus von $214 \mathrm{~g}$ gegenüber der Gruppe, welche mit neuem Mais gefüttert wurde, ergibt.

Das letzte Gewicht ergibt ein Plus von $427 \mathrm{~g}$ für die mit neuem Mais gefütterte Gruppe und $632 \mathrm{~g}$ für die mit altem Mais gefütterte.

Der Verdauungskoeffizient, d. h. das Verbältnis zwischen dem eingenommenen und dem assimilierten ist gesteigert für den alten Mais, ein Beweis, dass die. Nahrungsstoffe aus diesem Maise von dem Organismus besser ausgenutzt werden. 
Die Harnsäure, das Hauptelement unter den Stoffwechselprodukten der Eiweissstoffe bei den Vögeln, ist bei den mit altem Mais gefütterten Vögeln sowohl im allgemeinen während des Experiments, als auch in bezug auf das $1 \mathrm{~kg}$-Gewicht während 24 Stunden gesteigert. Auch der Harnstickstoffkoeffizient, d. h. das Verhältnis zwischen dem $\mathrm{N}$ der Harnsäure und dem Reste des $\mathrm{N}$ aus dem Harne, ist gestejgert. Daher die Andeutung, dass die Eiweissstoffe des alten Maises besser ausnutzbar sind wie die des nenen.

Die Stickstoffbilanz ergibt ein Plus für den mit altem Mais gefütterten Organismus, d. h. ein Teil der Eiweissstoffe dieses Maises sind in Eiweissstoffe umgewandelt, welche dem Organismus eigen sind. Multipliziert man die Ziffer des vom Organismus retinierten Stickstoffes mit dem Koeffizienten 6,25, so erhält man die Menge der vom Organismus als körpereigene Eiweisstoffe retinierten Stickstoffsubstanzen: $11,20 \mathrm{~g}$ für die mit altem Mais, 9,06 für die mit neuem Mais gefütterte Gruppe.

Aus den Resultaten der zweiten Reihe von Experimenten an Hähnen wiederholen wir folgendes:

Hähne (28. 0ktober 1912 bis S. Dezember 1912).

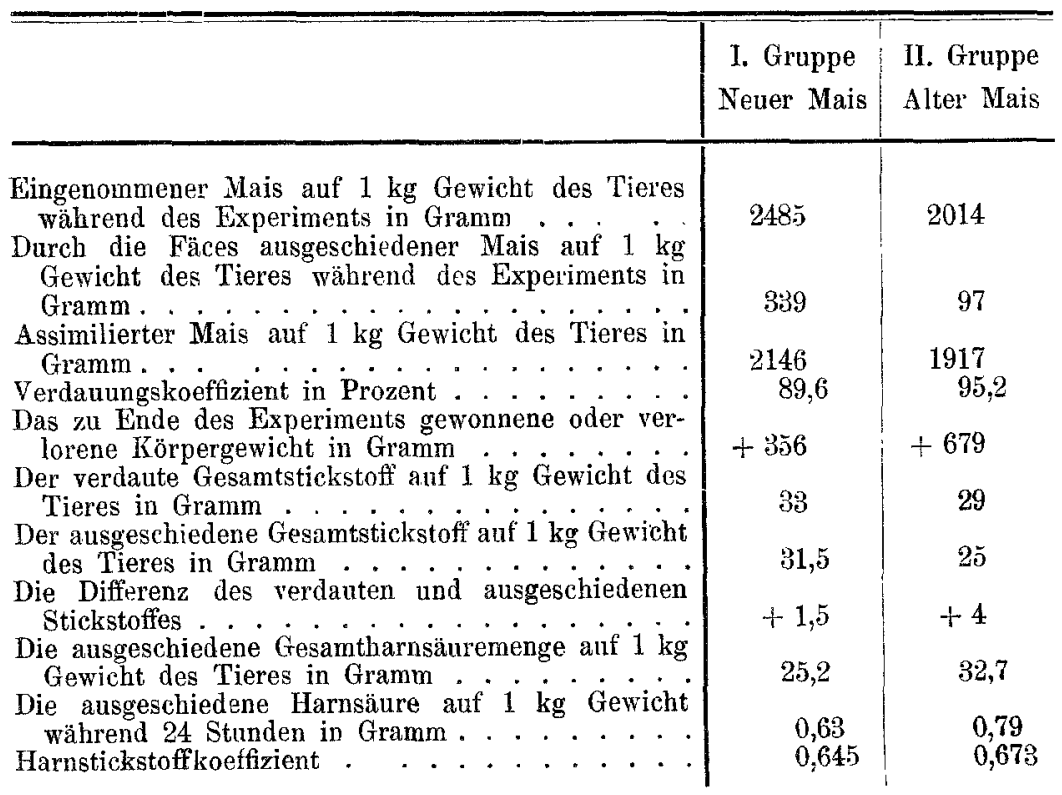


Man sieht genau, dass die oben angedeuteten Differenzen zwischen den Stoffwechselprodukten der mit altem und mit neuem Mais gefütterten Hühner auch hier noch bedeutende sind. Trotzdem die Ziffer des neu eingenommenen Maises grösser ist als die des alten, sowohl nach den Serien als auch im allgemeinen, so ist das Körpergewicht der mit altem gegenüber den mit neuem Mais gefütterten Hähnen doch doppelt so gross. Die Ausscheidung des neuen Maises als unnutzbar ist beinahe viermal grösser als die des alten.

Auch hier ist der Verdauungskoeffizient grösser für den alten Mais als für' den neuen.

Die Stickstoffbilanz ergibt für beide Gruppen ein grösseres Plus für den Organismus bei den Vögeln, was durch die Assimilationsnotwendigkeit von grossen Eiweissmengen erklärbar wäre, da die Hähne sich in der Wachstumsperiode befanden. Sehr eindeutig war die Tatsache, dass die vom Organismus retinierte Stickstoffmenge bei den mit altem Mais gefütterten Hähnen bedeutend grösser war, als diejenige bei den mit neuem Mais gefütterten. Multipliziert man die Ziffer des retinierten Stickstoffes mit dem Koeffizienten 6,25, so bekommt man $25 \mathrm{~g}$ Eiweiss für die erste Gruppe, $9,80 \mathrm{~g}$ für die zweite. Daher soll man die Tiere in der Wachstumsperiode mit altem Mais füttern. Die Ziffer der Harnsäure und des Harnstickstoffkoeffizienten geben dieselben Resultate wie in früheren Experimente.

Die bedeutendere Gewichtszunahme bei den mit altem Mais gefütterten Vögeln ist infolge einer besseren Ausnutzung der Kohlehydrate und der Stickstoffsubstanzen dieses Maises erklärlich.

Aus den Resultaten des dritten Experiments, welches an Ratten gemacht wurde, dessen Gesamtresultat wir nach $1 \mathrm{~kg}$-Gewicht des Tieres in der auf S. 315 befindlichen Rekapitulationstabelle wiedergeben, bemerken wir neuerdings Tatsachen, die die oben erwähnten bestätigen.

Auch hier ist die eingenommene Maismenge grösser bei der Rattengruppe, welche mit neuem Mais gefüttert sind. Bei denselben ist die durch die Fäces ausgeschiedene Maismenge grösser als bei den mit altem Mais gefütterten, während der Verdauungskoeffizient für den alten Mais grösser ist. 
Die ausgeschiedene Gesamitharnstoffmenge, und auf $1 \mathrm{~kg}$ Körpergewicht innerhalb 24 Stunden, sowie der Harnstickstoffkoeffizient dentet ebenfalls auf eine bessere Assimilation der Eiweissstoffe aus dem alten Mais hin.

Bei beiden Gruppen steigt anfangs das Körpergewicht, nach einer relativ kurzen Zeit (etwa 3 Wochen) beginnt es zu fallen.

Ratten (23. Oktober 1918 bis 25. November 1913).

\begin{tabular}{|c|c|c|}
\hline & $\begin{array}{l}\text { I. Gruppe } \\
\text { Neuer Mais }\end{array}$ & $\begin{array}{l}\text { II. Gruppe } \\
\text { Alter Mais }\end{array}$ \\
\hline 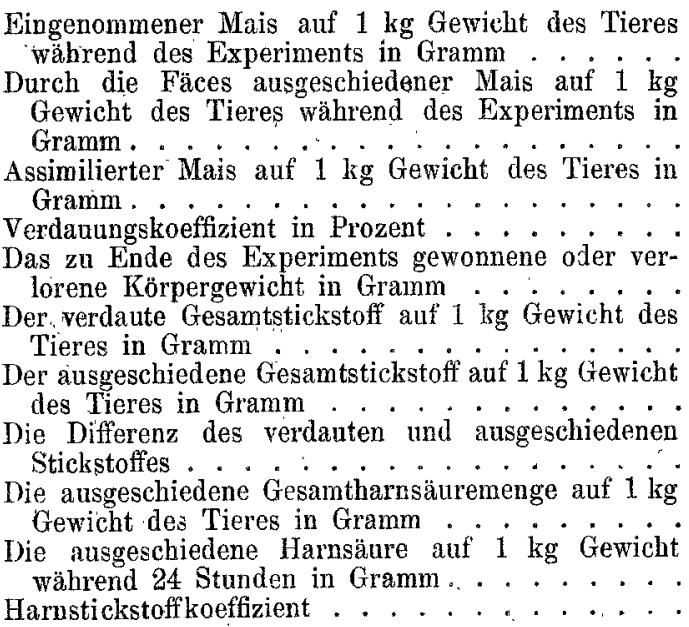 & $\begin{array}{c}2868 \\
223 \\
2645 \\
92,3 \\
-35 \\
38,2 \\
38,8 \\
-0,6 \\
43,1 \\
1,29 \\
0,934\end{array}$ & $\begin{array}{c}2049 \\
114 \\
1985 \\
95,4 \\
-2 \\
34,8 \\
34,02 \\
+0,78 \\
49,5 \\
1,49 \\
0,954\end{array}$ \\
\hline
\end{tabular}

Während bei der mit neuem Mais gefütterten Gruppe der Abfall derart rapid ist, dass die Gewichtsbilanz zu Ende des Experiments ein Minus vion $33 \mathrm{~g}$ gegenüber dem Anfangsgewichte ergibt, fällt das Gewicht bei der mit altem Mais gefütterten Gruppe viel Iangsamer herunter, so dass wir zum Schluss des Experiments nur eine Differenz von $2 \mathrm{~g}$ gegenüber dem Anfangsgewichte finden.

Die Stickstoff bilanz (sehr lehrreich, weil es die Gewichtskurve befolgt) ergibt bei der mit neuem Mais gefütterten Gruppe ein Defizit für den Organismus von 0,6 , was einen Verlust von $3,750 \mathrm{~g}$ von eigenem Körpereiweiss bedeuten würde; bei der anderen Gruppe dagegen ergibt die Stickstoff bilanz eine Zunahme von 0,78 .

Aus dem Ganzen folgt somit, dass der neue Mais schwerer zu verdauen und vom Organismus zu assimilieren ist als der alte. 


\section{Zusammenfassung.}

1. Aus unseren Untersuchungen geht hervor, dass der neue Mais weniger verdaulich und assimilierbar als der alte ist.

2. Die ausschliesslich mit Mais gefütterten Tiere fangen nach einer geraumen, von der Gattung abhängigen Zeit zu leiden an; dann werden sie mager und sterben, schneller aber diejenigen, welche mit neuem Mais ernährt wurden.

3. Diese Übelstände sind darauf zurückzuführen, dass das Eiweiss des Maises kein Tryptophan und nur. wenig, Glykokoll and Lysin enthält. 